\title{
Progress Toward the Development of an Aircraft Icing Analysis Capability
}

Robert J. Shaw

Lewis Research Center

Cleveland, Ohio

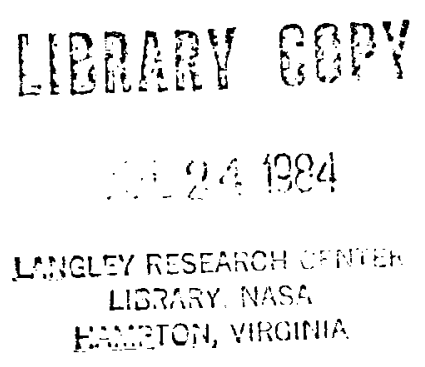

Prepared for the

Twenty-second Aerospace Sciences Meeting sponsored by the American Institute of Aeronautics and Astronautics Reno, Nevada, January 9-12, 1984 
PROGRESS TOWARD THE DEVELOPMENT OF AN AIRCRAFT ICING ANALYSIS CAPABILITY

\author{
Robert J. Shaw \\ National Aeronautics and Space Administration \\ Lewis Research Center \\ Cleveland, Ohio 44135
}

\title{
SUMMARY
}

An overview of the NASA efforts to develop an aircraft icing analysis capability is presented. Discussions are included of the overall and long term objectives of the program as well as current capabilities and limitations of the various computer codes being developed. Descriptions are given of codes being developed to analyze two and three dimensional trajectories of water droplets, airfoil ice accretion, aerodynamic performance degradation of components and complete aircraft configurations, electrothermal deicer, and fluid freezing point depressant deicer. The need for bench mark and verification data to support the code development is also discussed.

\section{INTRODUCTION}

The aircraft icing problem has long been researched and studied. Reports exist in the literature which trace icing research activities back as early as the late 1920's (ref. 1). Since then research into the aircraft icing problem has been an almost ongoing effort at varying levels of intensity by a number of government and private research organizations both in this country as well as in many other countries. A common thread which binds these various activities is that for the most part they have been experimental in nature. A majority of these programs have been aimed at studying the performance of various ice protection systems, although some limited attempts have been made to develop icing analys is capabilities.

The current NASA Aircraft Icing Research Program which was started in 1978 (ref. 2) seeks to take advantage of available computational fluid dynamics capabilities and develop a series of compatible computer codes which will address what is perceived to be the fundamental icing problems. Once these initial codes are developed, additional codes will then be developed to broaden and enhance the capabilities. The computer codes will be thoroughly evaluated by comparison with appropriate verification data. The development of these computer codes and the acquisition of the required verification data bases are two major goals of the NASA aircraft icing research program.

The purpose of this survey paper is to present the long term objectives of the icing analysis program as well as discuss the current capabilities and limitations of the various computer codes currently under development. Discussions are also given of the need for supporting experimental research to support the code development and verification. The following section gives the historical background of icing analys is development efforts. 
SYMBOLS

$\begin{array}{ll}C_{d} & \text { airfoil drag coefficient } \\ C_{\ell} & \text { airfoil lift coefficient } \\ M_{\infty} & \text { free stream Mach number } \\ \operatorname{Re} & \text { free stream Reynolds number } \\ \frac{x}{C}, \frac{y}{C} & \text { nondimensional airfoil coordinates } \\ \alpha & \text { airfoil angle-of-attack }\end{array}$

HISTORICAL BACKGROUND

As indicated, limited attempts have been made over the years to develop analytical capabilities to treat various aspects of the aircraft icing problem. Analys is of water droplet trajectories dates back to the 1940's and the work of Taylor (ref. 3) and Langmuir and Blodgett (ref. 4). The Languir Blodgett studies involved calculations of water droplet trajectories about circular cylinders for a wide variety of conditions using a differential analyzer.

However, as reference 5 indicates:

"Droplet trajectories about bodies with unknown or complex flowfields are difficult to obtain with a differential analyzer. Therefore, a wind tunnel method using a dye tracer technique to obtain experimentally the impingement characteristics of bodies has been developed..."

This lack of ability to predict flow fields, about even simple two dimensional, single element airfoil sections dictated that the early icing research efforts would be primarily experimental in nature. The NACA icing research effort which lasted from the early 1940's to the late 1950's, and has been the most intensive program to date, was primarily experimental although water droplet trajectories were calculated for a few airfoils and other simple geometry bodies for which velocity fields could be prescribed (refs. 6 to 23 ).

Although the NACA program was terminated in the late 1950 's, active icing research efforts were either continued or begun by other government agencies and private companies. As computer codes were developed during the 1960 's and 70 's to analyze fluid dynamic problems, groups which were then active in icing research developed capabilities for predicting water droplet trajectories about general two dimensional airfoil sections and simple inlet configurations. (e.g., refs. 24 to 28). For the most part, these computer codes were not then (and are still not) available in the open literature and thus remain proprietary.

More recently, attempts have been made to develop codes to predict the two dimensional ice accretion shapes on cylinders (refs. 29 to 30) and airfoils (refs. 31 to 33). The computer codes discussed in references 29, 30 , and 32 , while available in the open literature, are all limited in application. The code discussed in reference 33 is the most general in nature, but is not available for general distribution. In addition, none of the ice accretion codes has been thoroughly evaluated by comparison with enough experimental verification data to determine code capabilities and limitations. 
The prediction of aerodynamic performance degradation of an airfoil, due to leading edge ice accretions, has received only a limited attention. Reference 34 reported the resuits of attempts to calculate airfoil performance with idealized rime-like leading edge ice accretions. The conclusion of this limited study was that current airfoil analys is computer codes significantly underpredicted the drag for the airfoil with the leading edge accretion.

Predictions of unprotected aircraft performance degradation due to icing have been made for fixed wing (refs. 35 to 36) and rotary wing (ref. 37) applications. The efforts used the same basic component breakdown approach in conjunction with available experimental aerodynamic performance degradation data to predict overall vehicle performance degradation. All of the studies involved calculations for specific vehicles and icing and environmental conditions.

The only ice protection systems which have been modeled to date have been the electrothermal and hot gas systems used to anti or deice airfoils and inlets. Most of the efforts have been devoted to modeling the anti-icing problem (refs. 38 to 40) although some attempts have been made to treat the de-icing probiem (refs. 27, 41, and 42).

Thus, to date limited progress has been made in developing a unified aircraft icing analysis capability. As indicated in the preceding paragraphs, research groups have developed individual computer codes to handle current problems of interest, but no attempt has been made to formulate a plan for developing a unified series of computer codes which could address more general classes of icing problems. Also, many of the computer codes already developed have remained proprietary and; thus, many efforts have been needlessly duplicated.

Also, very little fundamental icing data currently exists in the open literature which is suitable for rigorously evaluating code capabilities and limitations. This may at first seem surprising since aircraft icing research activities date back to at least the 1920 's, but as already mentioned, a majority of the past experimental work has been dedicated to studying the performance characteristics of various ice protection systems. As such, the necessary detailed measurements were not made which would make the resulting data particularly useful for the icing analyst. In addition, the measurements which are required to be made to develop icing computer code verification data bring attention to the difficult instrumentation problems associated with acquiring accurate icing cloud environmental data and detailed aerodynamic flowfield performance data. Many of these instrumentation problems have not yet been solved and remain active research topics (ref. 2). Finally, while computational fluid dynamics research has been ongoing for several decades, only in the past 10 to 15 years have computer size and speed capabilities advanced to the point that it has become feasible to attempt to develop a unified icing analysis capability. In addition the availability of even more powerful computers (so called Class VI machines today and the National Aerodynamic Simulator or NAS for the mid to late 1980's) makes it feasible to consider analyzing such complicated icing problems as the unprotected helicopter rotor in forward flight from a fundamental approach.

The following section will discuss the long term objectives of the NASA aircraft icing analysis program. 


\section{OVERALL OBJECTIVES}

The long range objective of the NASA aircraft icing analysis program is to develop a capability to predict the details of an aircraft icing encounter for both fixed and rotary wing vehicles. Included in these predictions would be the change in aircraft performance and handling characteristics due to ice accretions on unprotected and deiced components as well as to ice protection system performance. This is obviously a lofty objective which will require many years of effort, both to develop the computer codes and to conduct the required verification/modeling experiments. However, before a detailed analysis capability for complete aircraft configurations can be contemplated, codes capable of predicting component performance in icing must be developed and verified. This suggests that an evolutionary path exists for icing code development, and figure 1 shows two such proposed paths - one for external icing problems and one for internal propulsion system icing problems.

A majority of the current code development/verification efforts are directed toward the two dimensional airfoil problem. Once the capability to analyze the two dimensional airfoil has been developed and the accuracy verified, it will serve as the basis for developing a fundamental analytical capability for treating wings, propellers, and helicopter rotors.

As figure 1 indicates, a similar evolutionary path can be advanced for propulsion system icing problems. However, the development of icing analysis codes to handle such internal flow problems is hampered by an inability to analytically model the highly three dimensional flows which exist in inlet configurations of current interest (e.g., flush mounted, highly integrated helicopter inlet configurations). For the immediace future the development of icing analysis capabilities must be restricted to more simple inlet configurations such as the axisymmetric geometries as depicted in figure 1.

Obviously a large number of computer codes are required in order to develop an overall aircraft icing analysis capability. Figure 2 shows the codes required and some (but by no means a 11 ) of the interfaces required to develop a unified methodology.

The shaded boxes in figure 2 indicate those computer codes currently under development and verification. As the figure indicates, there are many computer codes which are not currently being developed. While available resources certainly limit the number of codes which can be developed concurrently, another even more significant limitation is a lack of knowledge of appropriate fundamental physics on which to base computer models. For example, the lack of understanding of basic structural and fracture properties of impact ice make it impossible to develop a mathematical model of the pneumatic boot, one of the oldest of all ice protection systems. Similar comments can be made with regard to the electromagnetic impulse system.

Thus, before computer codes can be developed to treat various aspects of the aircraft icing problem, a series of basic modeling experiments first must be conducted in order that the key physical elements be incorporated in any subsequent mathematical models which are formulated.

Figure 2 also points out that an integral part of the icing analysis methodology under development are aerodynamic analysis codes for both indi$v i d u a l$ components and even complete aircraft configurations. Since these codes have historically been developed for analysis of aerodynamic performance in 
nonicing environments, their use to study icing problems will require that significant modifications and improvements be made. Obviously, the more robust and accurate these codes are, the more robust and accurate the icing analysis methodology will be.

The following sections of the paper will discuss in detail the particular codes being developed as indicated in figure 2 .

\title{
DISCUSSION OF ICING COMPUTER CODES
}

\author{
Water Droplet Trajectory Analysis
}

A knowledge of the water droplet trajectories about any component provides the first indication of that component's susceptibility to icing. Trajectory analysis about simple geometries was made as early as the 1940's by Taylor in England and Langmuir and Blodgett in the United States. The governing differential equations for water droplet motion are well known with the only significant empiricism being the expression for the droplet drag coefficient. An uncoupled approach is used in trajectory analysis - that is the water droplets are assumed to have no discernible effect on the aerodynamic flowfield.

Two major considerations in the development of a trajectory analys is capability are the choice of a flowfield computer code and the method used to pass flowfield information from the flowfield code to the trajectory analysis code. The NASA two dimensional trajectory analysis uses an incompressible, potential flow panel code developed by Hess-Smith (ref. 43). Trajectory calculations can be made for single and multi-element isolated airfoils, airfoil configurations with surrounding wind tunnel walls, and two dimensional inlets (ref. 44).

Calculations are performed for water droplets of a specified diameter or for a specified spectrum of droplet sizes. A second version of the trajectory code has been developed which is compatible with a Hess-Smith panel code for axisymmetric inlet geometries. This allows water droplet trajectories to be calculated in the inlet symmetry plane for any inlet angle-of-attack.

The flowfield computed by the appropriate Hess-Smith panel code is passed to the water droplet trajectory code through a data file which contains the computed source and vorticity strengths for each panel as well as the required panel geometry characteristics. Flowfield velocity components at positions required by the trajectory code are calculated by summing the contributions of each panel.

This approach of saving all required panel information and summing the contributions of all panels for each trajectory spatial step is termed the direct approach. An alternate scheme that has been employed in the past is a so called grid generation approach. The user specifies a fixed grid of points and the flowfield velocity components are calculated at each grid point in space and then the results are stored. In order to calculate flowfield velocity components at positions required by the trajectory code, some grid interpolation scheme is used. While the direct approach will require additional computing time relative to that required by the grid generation scheme, it is felt that the accuracy of the trajectory calculations will be improved. Also, the direct approach removes the requirement that the user worry about setting 
up a grid with enough resolution near the airfoil surface to resolve accurately enough the local flow accelerations. The direct solution approach should result in a more user friendly trajectory code.

Historically, water droplet trajectory codes have been evaluated by comparisons with available airfoil collection efficiency data generated by NACA (e.g., ref. 5). In general, the codes appear to give reasonably good agreement with the experimental results which themselves may be subject to some appreciable errors. However, this data base is limited in scope and in particular confined to low speed studies of airfoil sections of interest to the aviation community in the 1940 to 1955 time period. No experimental collection efficiency data is available for modern technology airfoil sections. Such data obviously is required to validate trajectory codes for current airfoil configurations.

In addition, the existing collection efficiency data base was generated in the NASA Icing Research Tunnel (IRT), a facility which has a maximum test section velocity of $300 \mathrm{mph}$ (empty tunnel). With this significant free stream velocity limitation, it is impossible to determine the importance of varying levels of flowfield compressibility on water droplet trajectories and, hence, collection efficiency distributions. This knowledge becomes particularly important for applications such as the helicopter rotor and propeller where the outboard sections experience local Mach numbers approaching 1.0 .

Lacking such knowledge, water droplet trajectory analyses are oftentimes performed on helicopter rotor sections using incompressible flowfield codes. One exception to this is the trajectory code developed by the British Royal Aircraft Establishment (ref. 27) which uses the Garabidian-Korn airfoil code to generate the required flowfield. As part of the ongoing NASA/RAE joint icing research agreement, comparison calculations have been made of water droplet trajectories about a NACA 0012 airfoil for a variety of free stream Mach numbers, water droplet sizes, and airfoil chords using incompressible and compressible flowfield calculations as inputs into the respective NASA and RAE trajectory codes. Typical results are shown in figure 3 where it can be seen that flowfield compressibility did not appear to have a significant effect on the collection efficiency curves for Mach numbers as high as 0.6 . While these preliminary results are encouraging and are in agreement with earlier NACA predictions (ref. 13), an adequate data base for airfoil high speed collection efficiencies is also required to verify the trajectory analyses.

In addition, it should be pointed out that essentially no collection efficiency data exists for inlet configurations. Thus, the capability of the NASA trajectory code for predicting water droplet trajectories about and through either two dimensional or axisymmetric configurations cannot be evaluated. This certainly must be regarded as a shortcoming in the code development process for inlets and the required data should be obtained to allow an orderly development and verification of the analysis code.

The NASA trajectory code for airfoils is an integral part of the airfoil ice accretion prediction code which will be discussed in the next section. As part of the ice accretion code, the airfoil flowfield and the resulting water droplet trajectory characteristics are periodically recomputed as the airfoil accretes ice and, hence, the effective body shape (airfoil and ice accretion) changes. Clearly, as the airfoil leading edge becomes more and more distorted 
due to the rough, irregular ice accretions, viscous effects become more important and the use of an inviscid code to predict the flowfield becomes a more serious question. At some point in the ice accretion process, a viscous code (or codes) must be used, but heretofore, no experimental data existed to assist in the flowfield modeling and code evaluation efforts. In addition, no collection efficiency levels have been measured for airfoils with leading edge ice accretions (either real or artificial).

Recently NASA initiated efforts to measure the properties of flowfields about two dimensional bodies with leading edge ice accretions and some initial results for cylinder icing shapes are shown in figure 4. The figure shows two 15 minute cylinder ice accretions measured in the NASA IRT for rime and glaze icing conditions. Also shown are the corresponding surface velocity distributions measured using instrumented two dimensional artificial ice shape models tested in another facility at NASA Lewis and predictions of the surface velocity distributions made with the Hess-Smith potential flow panel code used in the NASA two dimensional trajectory analysis code.

While the potential flow predictions do exhibit some erratic behavior near the stagnation point, namely several changes in sign of the local velocity, the overall agreement with the experimental data is surprisingly good. The large difference shown for the glaze ice shape for surface angles greater than $30^{\circ}$ to $35^{\circ}$ is due to massive boundary layer separation which, of course, is not modeled by a potential flow analysis. The nature of the prediction in the stagnation point region appears to be due to the locally rough distribution of coordinates of the ice shapes. Smoother distributions would most likely result in fewer sign changes in the local velocity predictions.

Efforts are continuing to evaluate the Hess-Smith potential flow panel code as well as other candidate inviscid and viscid codes against cylinder ice shapes such as those shown in figure 4, and against comparable airfoil data which has been generated (ref. 45). Efforts are also underway to significantly increase this data base for both low and high speed cases.

As already indicated, it is extremely important to understand the limitations of using a potential flow code in conjunction with a trajectory analysis code for calculating accurate droplet trajectories about an airfoil which is accreting ice. Initial NASA attempts to better understand this problem have involved developing an experimental technique to qualitatively ascertain local collection efficiency characteristics about an airfoil with a leading edge ice accretion. One typical result shown in figure 5 taken from reference 46 shows a short duration rime growth deposited on initial rime and glaze ice accretions. Since water droplets freeze immediately upon impact for rime icing, the ice accretion shape gives an indication of local collection efficiency distribution. The figure shows that for the glaze ice accretion the collection efficiency appears to be the highest in the immediate vicinity of the so called horns while only a small amount of water impinges in the region near the stagnation point.

Experiments must be conducted that will quantify results such as those shown in figure 5 in order to acquire the required collection efficiency data base. One approach to this would be to use the dye tracer technique employed by NACA (ref. 5). 
In order to calculate trajectories about components such as swept wings, general inlet configurations, and even complete aircraft configurations, a three dimensional trajectory analysis code is required. NASA has developed such a code and a preliminary version is discussed in reference 47 which calculates trajectories about three dimensional nonlifting bodies. This trajectory code also uses a Hess-Smith potential flow panel code to calculate three dimensional flowfields about bodies of interest. Again the direct solution approach is employed to pass flowfield information to the trajectory code.

The latest version of this code currently under development will predict trajectories about three dimensional lifting bodies. It will be used to study water droplet trajectories about the NASA icing research aircraft to assist in icing instrumentation studies. A digital description of this aircraft (a DeHavilland DHC6 Twin Otter) which has been prepared for the trajectory code is shown in figure 6 . Approximately 3500 panels were required to describe the aircraft. Clearly, the calculation of three dimensional trajectories about complete aircraft configurations such as the Twin Otter, will require significant computational resources.

The three dimensional trajectory analysis code also provides a potential tool to study trajectories of other particles such as snowflakes and ice crystals and even finite size ice pieces in the vicinity of aircraft. However, before such trajectories can be calculated, expressions must be input into the code for force coefficients ( 1 ift, drag, and moment), and in general such expressions do not presently exist.

\section{Airfoil Ice Accretion Analysis}

The NASA airfoil ice accretion analysis code which is called LEWICE is an extension of the work of Lozowski, Stallabraas, et al. (ref. 29) and Ack ley and Templeton (ref. 30). The LEWICE code predicts the ice growth rate distribution (and thus ice shape) around the leading edge of the airfoil by locally solving the quasi-steady icing energy balance equation first proposed by Messinger (ref. 48). The energy balance accounts for the governing heat and mass transfer processes occurring during the icing process such as convection to the free stream, latent heat release due to freezing, and aerodynamic heating. A more detailed discussion of the LEWICE code is given in reference 49.

A key input into any ice accretion analysis code is the surface convective heat transfer coefficient distribution about the body. The LEWICE computer code currently has an integral model for laminar, transitional, and turbulent boundary layer development which attempts to account for distributed surface roughness when predicting the heat transfer coefficient distribution.

As already indicated, the NASA two dimensional trajectory analysis code and the Hess-Smith potential flow panel codes are incorporated in the LEWICE code. This allows the user to periodically update the potential flowfield and droplet trajectory calculations as the ice accretion distorts the airfoil leading edge. This updating of the local collection efficiency characteristics should contribute to an improved accuracy in the numerical modeling. However, as has already been noted at some point in the process, the rough, irregular leading edge ice accretion will distort the airfoil flowfield to the degree that a viscous code will be required to adequately model the flowfield. 
Difficulties have been encountered with the LEWICE code to date, that as the ice accretes on the airfoil, the predicted coordinates of the ice shape tend to become somewhat rough and the potential flow panel code produces a correspondingly rough prediction of the flowfield. This appears to be particularly true for the glaze ice accretion predictions. Figure 4 which has already been discussed shows this result for predicted surface velocity distributions on the cylinder rime and glaze ice shapes.

Currently, it is felt that some sort of coordinate smoothing capability must be incorporated into the LEWICE code to control the roughness of the ice accretion shape coordinates prior to being input into the potential flow code. However, it must be borne in mind that any smoothing approach employed must be such that the essential features of the calculated ice shape are preserved. clearly, this will be an active research topic for sometime.

Previous studies (e.g., ref. 29) have shown that a different specifications of the surface convective heat transfer coefficient distribution about the body will yield significantly different ice accretion shapes. This specification of heat transfer coefficient distribution is complicated by the fact that the ice accretion shape is irregularly shaped with a significant amount of surface roughness. Available experimental data for surface heat transfer coefficients were virtually nonexistent before NASA initiated efforts to acquire such data. Reference 50 reports on heat transfer coefficient measurements made for simulated ice shapes on a cylinder.

Figure 7 shows the predictions of heat transfer coefficient distributions using the LEWICE integral boundary layer routine for two selected cylinder ice shapes compared with experimental results taken from reference 50 . For both the rime and glaze ice shapes the boundary layer model significantly underpredicts the observed local maximums in heat transfer coefficient.

Clearly the LEWICE code is still very much a research code. Many numerical studies and experimental comparisons remain to be done before the code accuracies and 1 imitations can be thoroughly verified and the code made available to the user community. Also, the LEWICE code is intended to predict representative two dimensional ice accretion shapes for airfoils. Highly three dimensional ice accretions such as those which can occur on highly swept wings cannot be predicted by LEWICE, and it is felt that such predictions will remain beyond the state of the art for the foreseeable future.

\section{Aerodynamic Performance Degradation Analysis}

Accurate predictions of aerodynamic performance degradation of a component or a complete aircraft is one of the desired end products of the icing analysis methodology depicted in figure 2. Currently, the development and verification of computer codes to predict airfoil performance degradation is the prime research topic, but some more empirically based approaches for predicting degradations of propeller, helicopter rotor, and even complete aircraft configurations are also being developed. As already indicated, it is necessary to develop an analytical capability to analyze the two dimensional airfoil case before attempts can be made to analyze more complicated configurations with a fundamental approach. 
When the two dimensional airfoil problem is considered, one is immediately struck by its complexity. Airfoil ice accretion shapes are extremely rough and irregular with rather large surface roughness elements present especially for glaze accretions (fig. 8). It seems that, at best, an analysis capability can be developed that will handle ice accretion shapes that hopefully would represent the gross cross sectional details with the surface roughness effects being accounted for through an empirical treatment in the viscous portion of the analysis.

Since rime ice accretions are generally more smoothly contoured in cross section, initial efforts have been to attempt to predict airfoil performance degradation for rime ice icing conditions and compare with available experimental data. Results to date have shown that conventional airfoil analysis codes used by the industry cannot predict drag levels as high as those measured for typical rime ice shapes (ref. 51). It is felt that this is due to an inability in the codes to treat wall roughness effects other than by promoting earlier boundary layer transition. The levels of surface roughness present on rime ice accretions appear to significantly increase the momentum losses occurring within the boundary layer resulting in the higher drag levels observed.

The short term solution to this problem was to develop an empirical drag coefficient correction equation to modify the drag levels predicted by the airfoil code. This correlation was based on a limited airfoil rime ice data base. Details concerning this correlation are given in reference 52 . Figure 9 shows the prediction of airfoil performance for the NACA 65A413 section for two configurations - smooth model with no ice accretion and model with a stylized rime ice accretion which was roughened by application of sand grains of average height-to-chord ratio of 0.0025 . The term stylized ice accretion refers to an ice shape which is predicted or estimated while an artificial ice accretion is one which is constructed using tracings, castings and/or photographs of actual ice accretions. Comparable experimental data is also shown which was acquired in an airfoil wind tunnel. The predictions were made with the Eppler airfoil code with the predicted drag levels for the rime ice shape modified by the empirical correlation already discussed. As expected, the predicted results agreed well with the experimental measurements for the clean airfoil. However, the agreement was less satisfactory for the stylized rime ice shape although it was better than that observed for the predictions made using the old NACA drag correlation expression for airfoil icing (ref. 53) which are also shown. It should be noted that this NACA correlation is still in use today.

Currently work is underway to adapt an integral boundary layer formulation by Dvorak (ref. 54) which attempts to account for boundary layer momentum losses due to surface roughness. Current status of this work is discussed in reference 55. Figure 10 shows code predictions for an airfoil both with and without total upper surface roughness compared to wind tunnel test results. Note that when transition was specified to occur at 5 percent chord, the code only predicted a small increase in drag, but when the momentum loss associated with the upper surface roughness was accounted for, the code predictions agreed well with the experimental data.

Detailed analysis of the flowfield about an airfoil with a glaze ice accretion presents even more complications than does the rime ice accretion. As figure 11 indicates, the shape of the glaze ice accretion will often result in separation - reattachment zones occurring aft of the horns on either top or 
bottom surfaces (if not both). When the boundary layer reattaches (which experimental evidence indicates it does for lower angles-of-attack), it will have a thick, highly distorted profile. A glaze ice analysis must be able to adequately model this separation - reattachment process as well as the boundary layer degradation due to roughness which exists on the ice accretion.

A flowfield analysis capable of treating the general glaze ice case must have two components: (1) inviscid flowfield prediction which can account for boundary layer displacement effects, and (2) viscous prediction which includes a separation - reattachment model and modeling of the surface roughness effects. The first step undertaken in developing this capability has been to evaluate various inviscid flowfield codes to determine which (if any) are appropriate for use. Currently, the Bristow mixed boundary, potential flow, panel code (ref. 56) appears to be an attractive candidate. This code allows for regions where the surface velocity can be input and the body shape predicted. Figure 12 shows the prediction of the dividing streamline aft of a typical glaze ice shape for which an experimentally determined pressure coefficient distribution was input. The predicted streamline agrees reasonably well with the dividing streamline inferred from flow visualization studies (oil drop tracings on a splitter plate) which were conducted.

Work is continuing to evaluate various candidate codes before a final selection is made. It should be borne in mind that the inviscid flow code which is ultimately chosen must be able to interface with the NASA water droplet trajectory code. As such, the code must accurately predict off body velocity components.

Currently, experimental programs are being planned and conducted to map in detail the required flowfield properties for airfoils with representative rime and glaze ice accretions. A comprehensive data base must be in hand before the glaze ice modeling effort can be carried much further. This data base will be used not only to guide the modeling effort but also to provide test cases for evaluating the analysis methodology which will be developed.

An alternate solution to the airfoil aerodynamic performance prediction problem might be to employ a Reynolds averaged Navier-Stokes analysis. Currently, a significant effort is being expended to develop and improve such codes, and with the increased computing power forecast for the near future (especially the National Aerodynamic Simulator or NAS) such an approach to treating the airfoil icing problem might be feasible. NASA has recently initiated an effort to evaluate the present capabilities of one such Navier-Stokes code to handle the airfoil icing problem. Initial results of this study are presented in reference 57. Clearly, this will be a long term effort. It is envisioned that considerable effort may be required to solve problems associated with grid generation and turbulence modeling for the iced airfoil problem.

Implicit in the discussion so far has been the assumption that meaningful iced airfoil flowfield data can be acquired using artificial or stylized ice accretions rather than actual ice accretions. The use of artificial ice accretions appears to be necessary due to a lack of proven instrumentation techniques for determining boundary layer development over an airfoil which is accreting ice.

Figure 13 gives one some confidence that it is possible to adequately simulate the effect of ice accretion on overall airfoil performance $\left(\Delta C_{d}\right)$ 
using wooden replicas fashioned from template drawings of ice accretions to which were added sand grains in order to simulate the surface texture or roughness of the ice accretion. Clearly, much more research is required to validate this simulation testing approach. If such artificial icing testing techniques cannot be verified, then new instrumentation techniques must be developed to allow the necessary flowfield data to be acquired with actual ice accretions.

The method of specifying the surface roughness present on an ice accretion must also be investigated in more detail. The approach to date has been to estimate roughness by measurements of actual ice accretions and then affix a similar height of grit roughness to the fabricated shapes. If one compares a closeup photograph of an actual rime ice accretion (fig. 14(a)) with that of an artificial ice shape with grit applied (fig. 14(b)) the differences can be seen to be significant. Again, much more work is needed in this area.

Currently, efforts are underway to improve the simulation technique by using silicone molds of ice accretions to fabricate artificial ice accretions (fig. 15). These accretions can be instrumented with surface static pressure taps to get detailed flowfield information. It is hoped that this approach will result in a more accurate simulation technique.

Efforts are also underway to develop aerodynamic degradation prediction methodologies for propellers (ref. 58), helicopter rotors (refs. 59 to 60), and complete aircraft configurations (ref. 61). By necessity, these approaches are presently based on correlations which relate component performance degradation to known or easily calculated aerodynamic and environmental conditions. These correlations are used along with a water droplet trajectory code and an aerodynamic performance code to predict aerodynamic performance degradation due to icing.

In particular, the studies done to date have used the rime ice correlation for airfoil performance degradation already discussed and, thus, they are at present limited in generality. To make these methodologies more general in applicability, a correlation (or correlations) must be used in the analysis which can predict with reasonable accuracy airfoil performance degradation due to glaze and mixed as well as rime ice conditions. Efforts are underway to develop such correlations and a number of different airfoil geometries will be tested in the NASA IRT to acquire the required data base to support this effort.

A major problem that exists with regard to the development of these performance methodologies is the almost complete lack of acceptable experimental data for making meaningful comparisons. The one exception to this is the propeller performance degradation data taken during the NACA icing research program (ref. 62). Those natural icing encounters reported in reference 62 which were judged to be rime icing encounters were used to compare with predictions made using the propeller degradation methodology developed (ref. 58). One typical comparison shown in figure 16 indicates a good agreement between predicted and measured propeller performance when compared on a propeller efficiency versus advance ratio basis. However, the agreement was not as good when comparisons were made on the basis of thrust and power coefficients. These results do give one some confidence in the approach used to develop the methodology. 
This same basic approach used to analyze the propeller has been applied to the helicopter rotor, both in hover (ref. 59) and in forward flight (ref. 60). However, no flight test data is available to make the needed comparisons. NASA currently has a joint program with the U.S. Army to acquire ice accretion/rotor aerodynamic performance degradation data for both hover and forward flight conditions (ref. 63). When this data base is available and the needed comparisons are made, needed improvements in the rotor analysis methodology will be made.

The rotor forward flight analysis poses some particularly difficult questions as to how to handle the lack of symmetry that exists about the rotor disc plane. In particular, how to subdivide the disc into sections and determine the contributions to overall rotor performance degradation of each section is not at all clear. Research efforts are continuing to improve the approach to treating rotor forward flight icing problem.

The overall aircraft performance prediction program being developed (ref. $61)$ relies on a component buildup approach. Experimental data and/or correlations are used to relate aerodynamic and icing conditions to resultant aerodynamic performance degradation for each component. The individual component degradations are then summed to give the overall aircraft performance degradation. A significant shortcoming of the aircraft performance code is the present inability to determine the contributions of components such as struts, landing gear, fuselage, and other miscellaneous appendages. Future IRT tests are planned to acquire such data.

In support of the development of the overall aircraft aerodynamic performance degradation prediction code, NASA is acquiring performance data in natural icing as part of the icing research aircraft flight program (ref. 64). The aircraft is selectively deiced after any icing encounter to determine the contributions of each component to overall performance degradation. Comparison component icing tests in the IRT are also being conducted.

\section{Ice Protection System Analysis}

The computer codes which have been discussed in the preceding paragraphs have treated either components or complete configurations with no ice protection. Of course, a complete icing analysis methodology must be able to analyze the various anti and deicing systems. As figure 2 indicates, there are many such systems.

Analytical prediction methods are currently under development to handle two ice protection systems - the electrothermal and fluid freezing point depressant systems. As figure 2 shows, computer models of several other ice protection systems remain to be developed. The development of such models is currently hampered by a lack of fundamental knowledge. In particular, for surface deflection deicing systems such as the pneumatic boot and electromagnetic impulse, information concerning ice adhesion and structural properties of impact ice must be acquired before the computer codes can be developed. NASA has recently initiated efforts to study both analytically and experimentally structural properties of impact ice and to analytically model the structural dynamics of the electromagnetic impulse deicing system (refs. 65 to 66). 
One and two dimensional transient heat conduction computer codes have been developed to model the electrothermal deicing system (refs. 67 and 68). These codes employ finite difference solutions to the appropriate transient heat conduction equation to predict the temperature at any point within the deicer assembly, including the ice layer, as a function of time. A unique feature of these codes is the ability to handle the moving water/ice interface which can occur during deicer operation. Available helicopter flight icing data taken with electrothermal deicers indicates that the interfacial temperatures (erosion shield/water (ice) interface) as high as $60^{\circ} \mathrm{F}$ are observed before shedding occurs (ref. 70). This indicates a finite thickness layer of water may exist between the ice and the erosion shield. Figure 17 taken from reference 71 indicates that the inclusion of the moving water-ice interface in the computer model does have a significant impact on the resulting predicted temperature profiles.

Currently, a two dimensional transient conduction code is under development which will handle actual airfoil geometries including a variable ice thickness distribution around the leading edge. This code will also treat the moving water/ice interface. The method employed is a coordinate mapping technique which will map the actual geometry into equivalent rectangular domain(s) where the appropriate finite difference equations are solved. A discussion of the current status of this code is given in reference 72 .

The series of transient heat conduction codes being developed are especially tailored to analyzing the electrothermal deicing problem which should make them easier to use than the larger more general transient heat conduction codes currently being used by the aerospace industry.

Currently, an experiment is planned for the IRT which will provide a verification data base for the electrothermal deicer codes. A section of a UH1H helicopter rotor (NACA 0012 airfoil section) with an electrothermal deicer installed has been instrumented with over 70 thermocouples. This rotor section will be tested over a wide range of aerodynamic and environmental conditions. Transient temperature profiles will be measured during the electrothermal deicing sequence and compared with model predictions.

A computer code based on a simple engineering model is currently being developed to predict anti-icing performance of the fluid freezing point depressant system (ref. 73). Figure 18 shows predicted minimum anti-icing flow rates compared with experimentally measured levels for a general aviation airfoil tested in the IRT. In general, the agreement is good. Some of the scatter is thought to be due to the experimental procedure used to determine minimum anti-icing flow rates which requires the experimentalist to make a subjective judgment of when the minimum flow has been reached. Work is continuing to refine the model and to acquire more experimental data for airfoils of different geometries.

\section{CONCLUSIONS}

NASA efforts to develop an aircraft icing analysis capability have obviously just begun and will require a long term effort. Nevertheless, many of the initial computer codes required to form a basic or core capability have been developed and are currently being evaluated. In particular codes have been developed to predict two and three dimensional trajectories of water 
droplets, airfoil ice accretion, aerodynamic performance degradation of components and complete aircraft due to icing, electrothermal deicer, and fluid freezing point depressant anti-icer. Bench mark and verification experiments have been defined and are being planned to support the code development.

\section{REFERENCES}

1. Carroll, T., and McAvey, W. H.: "The Formation of Ice Upon Exposed Parts of an Airplane in Flight," NACA TN 293, 1928.

2. Reinmann, J. J.; Shaw, R. J.; and 01sen, W. A.: "Aircraft Icing Research at NASA," NASA TM-82919, June 1982.

3. Taylor, G. I.: "Notes on Possible Equipment and Techniques for Experiments on Icing on Aircraft," ARC R M 2024, 1940.

4. Langmuir, I.; and Blodgett, K. B.: "A Mathematical Investigation of Water Droplet Trajectories," AAF-ATSC-Tech. Rpt. 5418, Feb. 1946.

5. Gelder, T. F.; Smyers, W. H.; and von Glahn, U.: "Experimental Droplet Impingement on Several Two-Dimensional Airfoils with Thickness Ratios of 6 to 16 percent," NACA TN 3839, 1956.

6. Brun, R. J.; Serafini, J. S.; and Moshos, G. J.: "Impingement of Water Droplets on an NACA 65-212 Airfoil at an Angle of Attack of $4^{\circ}$," NACA RM E52B12, 1952.

7. Hacker, P. T.; Brun, R. J.; and Boyd, B.: "Impingement of Droplets in $90^{\circ}$ Elbows with Potential Flow," NACA TN 2999, 1953.

8. Serafini, J. S.: "Impingement of Water Droplets on Wedges and DoubleWedge Airfoils at Supersonic Speeds," NACA Rep. 1159, 1954. (Supersedes NACA TN 2971).

9. Brun, R. J.; Gallagher, H. M; . and Vogt, D. E.: "Impingement of Water Droplets on NACA $65 A 004$ Airfoil and Effect of Change in Airfoil Thickness from 12 to 4 Percent at $4^{\circ}$ Angle of Attack," NACA TN 3047, 1953.

10. Brun, R. J.; Gallagher, H. M.; and Vogt, D. E.: "Impingement of Water Droplets on NACA $65_{1}-208$ and $65_{1}-212$ Airfoils at $4^{\circ}$ Angle of Attack," NACA TN 2952, 1953.

11. Hacker, P. T.; Saper, P. G.; and Kadow, C. F.: "Impingement of Droplets in $60^{\circ}$ Elbows with Potential Flow," NACA TN 3770, 1956.

12. Brun, R. J.; and Mergler, H. W.: "Impingement of Water Droplets on a Cylinder in an Incompressible Flow Field and Evaluation of Rotating Multicylinder Method for Measurement of Droplet-Size Distribution, Volume-Median Droplet Size, and Liquid-Water Content in Clouds, "NACA TN 2904, 1953.

13. Brun, R. J.; Serafini, J. S.; and Gallagher, H. M.: "Impingement of Cloud Droplets on Aerodynamic Bodies as Affected by Compressibility of Air Flow Around the Body," NACA TN 2903, 1953. 
14. Guibert, A. G.; Janssen, E.; and Robbins, W. M.: "Determination of Rate, Area, and Distribution of Impingement of Waterdrops on Various Airfoils from Trajectories Obtained on the Differential Analyzer, "NACA RM 9A05, 1949.

15. Dorsch, R. G.; and Brun, R. J.; "A Method for Determining Cloud-Droplet Impingement on Swept Wings," NACA TN 2931, 1953.

16. Brun, R. J.; and Dorsch, R. G.: "Impingement of Water Droplets on an Ellipsoid with Fineness Ratio 10 in Axisymmetric Flow, "NACA TN 3147 , 1954.

17. Dorsch, R. G.; Brun, R. J.; and Gregg, J. L.: "Impingement of Water Droplets on an Ellipsoid with Fineness Ratio 5 in Axisymmetric Flow," NACA TN 3099, 1954.

18. Dorsch, R. G.; and Brun, R. J.: "Variation of Local Liquid-Water Concentration about an Ellipsoid of Fineness Ratio 5 Moving in a Droplet Field," NACA TN 3153, 1954.

19. Brun, R. J.; Gallagher, H. M.; and Vogt, D. E.: "Impingement of water Droplets on NACA 65A004 Airfoil at $8^{\circ}$ Angle of Attack," NACA TN 3155 , 1954.

20. Brun, R. J.; and Dorsch, R. G.: "Variation of Local Liquid-Water Concentration about an Ellipsoid of Fineness Ratio 10 Moving in a Droplet Field," NACA TN 3410, 1955.

21. Dorsch, R. G.; Saper, P. G.; and Kadow, C. F.: "Impingement of Water Droplets on a Sphere," NACA TN 3587, 1955.

22. Lewis, W; and Brun, R. J.: "Impingement of Water Droplets on a Rectangular Half Body in a Two-Dimensional Incompressible Flow Field," NACA TN 3658, 1956.

23. Brun, R. J.; and Vogt, D. E.: "Impingement of Water Droplets on NACA 65A004 Airfoil at $0^{\circ}$ Angle of Attack," NACA TN 3586, 1955.

24. Schmidt, W. F.: "Water Droplet Impingement Prediction for Engine Inlets by Trajectory Anaiysis in a Potential Flowfield Sample Problem, "Boeing Co., D3-6961-1, Dec. 1965.

25. Werner, J. B.: "Ice Protection Investigation for Advanced Rotary-Wing Aircraft," USAAMRDL-TR-73-38, Aug. 1973.

26. Sova, G. J.: "Thermal Analysis Model for a Wing Leading Edge in Icing." Vol. 1, Rockwell Report NA79-357, July 1979.

27. Cansdale, J. T.: "Helicopter Rotor Ice Accretion and Protection Sixth European Rotorcraft and Powered Lift Aircraft Forum, "Bristol, England, Sept. 16-19, 1980.

28. Yoeman, K. E.: Private Communication. 
29. Lozowski, E. P.; Stallabrass, J. R.; and Hearty, P. F.: "The icing of an Unheated Non-Rotating Cylinder in Liquid Water Droplet: Ice Crystal Clouds," National Research Council of Canada, LTR-LT-96, Feb. 1979.

30. Ackley, S. F.; and Templeton, M. K.: "Computer Modeling of Atmospheric Ice Accretion," CRREL 79-4, March 1979.

31. Hankey, W. L.; and Kirchner, R.: "Ice Accretion of Wing Leading Edges," AFFDL-TM-79-85-FXM, June 1979.

32. Lozowski, E. P.; and 0leskiw, M. M.: "Computer Modeling of Time-Dependent Rime Icing in the Atmosphere," CRREL 83-2, Jan. 1983.

33. Cansdale, J. T.; and Gent, R. W.: "Ice Accretion on Aerofoils in TwoDimensional Compressible Flow: A Theoretical Model," RAE-TR-82128, Jan. 1983 .

34. Peterson, A. A.; and Dadone, L. U.: "Helicopter Icing Review," FAA-CT-80-210, Sept. 1980.

35. Leckman, P. R.: "Qualification of Light Aircraft for Flight in Icing Conditions," SAE Paper 710394, Mar. 1971.

36. Jackson, G. C.: "AEROICE - A Computer Program to Evaluate the Aerodynamic Penalties Due to Icing," AFFDL-TM-79-91-WE, 0ct. 1979.

37. Young, C.: "A Theoretical Study of the Effect of Blade Ice Accretion on the Power-0ff Landing Capability of a Wessex Helicopter, "Vertica, vol. 2,1978 , pp. 11-25.

38. Schmidt, W.F.: "Engine Inlet Thermal Anti-Icing Analyses Techniques," 8th Annual National Conference on Environmental Effects on Aircraft and Propulsion Systems, Bordentown, New Jersey, Oct. 1968, pp. 11-16.

39. Breeze, R. K.; Sova, G. J.; and Bandy, E. M.: "Analysis for Certification of Airframe Ice Protection Provisions on the Sabreliner NA-265-65 Airplane," Rockwell Report SR-79-005, Sept. 1979.

40. Heinrich, A.; Ross, R.; and Ganesan, N.: "Engine Inlet Anti-icing System Evaluation Procedure," FAA-RD-80-50, Jan. 1980.

41. Stallabrass, J. R., "Thermal Aspects of De-Icer Design, International Helicopter Icing Conference," Ottawa, Canada, May 23-26, 1972.

42. Stasa, F. L.; and Yeoman, K. E.: "Finite Element Thermal Analysis of an Icing Protection System," AIAA Paper 83-0112, Jan. 1983.

43. Hess, J.L. and Smith, A.M.0., "Calculation of Potential Flow About Arbitrary Bodies," Progress in Aeronautical Sciences," Vo1. 8, edited by D. Kuechemann, Pergaman Press, 1967, pp 1-138.

44. Chang, H. P.; Frost, W.; Shaw, R. J.; and Kimble, K. R., "Influence of Multidroplet Size Distribution on Icing Collection Efficiency, "AIAA Paper 83-0110, Jan. 1983. 
45. Zaguli, R. J.: "Potential Flow Analysis of Glaze Ice Accretions on an Airfoil," The Ohio State University Research Foundation, June 1983, (Also NASA CR to be published).

46. 0lsen, W. A.; and Shaw, R. J.: "Ice Shapes and the Resulting Aero Penalty for a Typical Helicopter Airfoil," AIAA Paper 84-0109, Jan. 1984.

47. Norment, H. G.: "Calculation of Water Drop Trajectories to and About Arbitrary Three-Dimensional Bodies in Potential Airflow, "NASA CR-3291, August 1980.

48. Messinger, B. L.: "Equilibrium Temperature of an Unheated Icing Surface as a Function of Airspeed," Journal of the Aeronautical Sciences, Vol. 20, Jan. 1953, pp. 29-42.

49. MacArthur, C. D.: "Numerical Simulation of Airfoil Ice Accretion," AIAA Paper 83-0112, Jan. 1983.

50. Van Fossen, G. J.; Simoneau, W. A.; 01sen, W. A.; and Shaw, R. J.: "Heat Transfer Distributions Around Nominal Ice Accretion Shapes Formed on a Cylinder in the NASA Lewis Research Tunnel," AIAA Paper 84-0017, Jan. 1984.

51. Bragg, M. B.; Gregorek, G. M.; and Shaw, R. J., "Wind Tunnel Investigation of Airfoil Performance Degradation Due to Icing, "AIAA Paper 82-0582, 1982 .

52. Bragg, M. B.: "Rime Ice Accretion and its Effect on Airfoil Performance," NASA CR-165599, Mar. 1982.

53. Gray, V. H.: "Prediction of Aerodynamic Penalties Caused by Ice Formation on Various Airfoils," NASA TN D-2166, 1964.

54. Dvorak, F. A.: "C $\mathrm{L}_{\text {max }}$ Program Description," AMI Report 7965, 1979.

55. Bragg, M. B.: "Predicting Airfoil Performance with Rime and Glaze Ice Accretions," AIAA Paper 84-0106, Jan. 1984.

56. Bristow, D. R.: "Development of Panel Methods for Subsonic Analysis and Design," NASA CR-3234, 1.980.

57. Potapczuk, M. G.; Chima, R. V.; Shaw, R. J.; and Gerhart, P. M.: "Evaluation of Iced Airfoil Performance Using a Navier-Stokes Equation Solver with a Body-Fitted Curvilinear Coordinate," AIAA Paper 84-0107, January 1984.

58. Korkan, K. D.; Dadone, L.; and Shaw, R. J.: "Performance Degradation of Propeller Systems Due to Rime Ice Accretion," Journal of Aircraft article to be published.

59. Korkan, K. D.; Dadone, L.; and Shaw, R. J.: "Helicopter Rotor Performance Degradation in Natural Icing Encounter," Journal of Aircraft article to be published. 
60. Korkan, K. D.; Dadone, L.; and Shaw, R. J.: "Performance Degradation of Helicopter Rotor Systems in Forward Flight Due to Rime Ice Accretion," AIAA Paper 83-0029, 1983.

61. Gregorek, G. M.; Bragg, M. B.; and Shilling, J. B.: "Performance Analyses for Aircraft in Icing Conditions," AIAA Paper 84-0180, Jan. 1984.

62. Neel, C. B.; and Bright, L. G.: "The Effect of Ice Formations on Propeller Performance," NACA TN 2212, 1950.

63. Abbott, W. Y.; Belte, D.; Williams, R. A.; and Stellar, F. W.: "Evaluation of UH-1H Hover Performance Degradation Caused by Rotor Icing," USAAEFA Report No. 82-12, Aug. 1983.

64. Ranaudo, R. J.; Mikkelsen, K. L.; McKnight, R. C.; and Perkins, P. J.: "Performance Degradation of a Typical Twin Engine Commuter Type Aircraft in Measured Nationul Icing Conditions," AIAA Paper 84-0179, Jan. 1984.

65. Schrag, R. L. and Zumwalt, G. W., "Electro-Impulse Deicing: Concept and Electrodynamic Studies," AIAA Paper 84-0021, Jan. 1984.

66. Bernhart, W. D. and Zumwalt, G. W.: "Electro-Impulse Deicing Structural Dynamics Studies, Icing Tunnel Tests and Applications," AIAA-84-0022.

67. Dewitt, K. J.; and Baliga, G.: "Numerical Simulation of One-Dimensional Heat Transfer in Composite Bodies with Phase Change - Wing De-Icing Pads," NASA CR-165607, 1982.

68. Marano, J. J.: "Numerical Simulation of an Electrothermal Deicer Pad," NASA CR-168097, 1983.

69. Chao, D. F.: "Numerical Simulation of Two-Dimensional Heat Transfer in Composite Bodies with Application to De-Icing of Aircraft Components," NASA CR to be published.

70. Private communication. A.A. Peterson, Boeing Vertol.

71. DeWitt, K. J.; Keith, T. G.; Chao, D. F.; and Masiulaniec, K. C.: "Numerical Simulation of Electrothermal Deicing Systems," AIAA Paper 83-0114.70, Jan. 1983.

72. Keith, T.G.; DeWitt, K. J.; Masiulaniec, K. C.; and Chao, D.: "Predicted Electrothermal Deicing of Aircraft Blades," AIAA Paper, 84-0110, Jan. 1984.

73. Kohlman, D. L.; and Albright, A. E.: "A Method of Predicting Flow Rates Required to Achieve Anti-Icing Performance with a Porous Leading Edge Ice Protection System," Kansas Univ. Center for Research, Inc., Lawrence, Kansas, KU-FRL-464-5-Rev-A, Aug. 1983. (NASA CR-168213). 


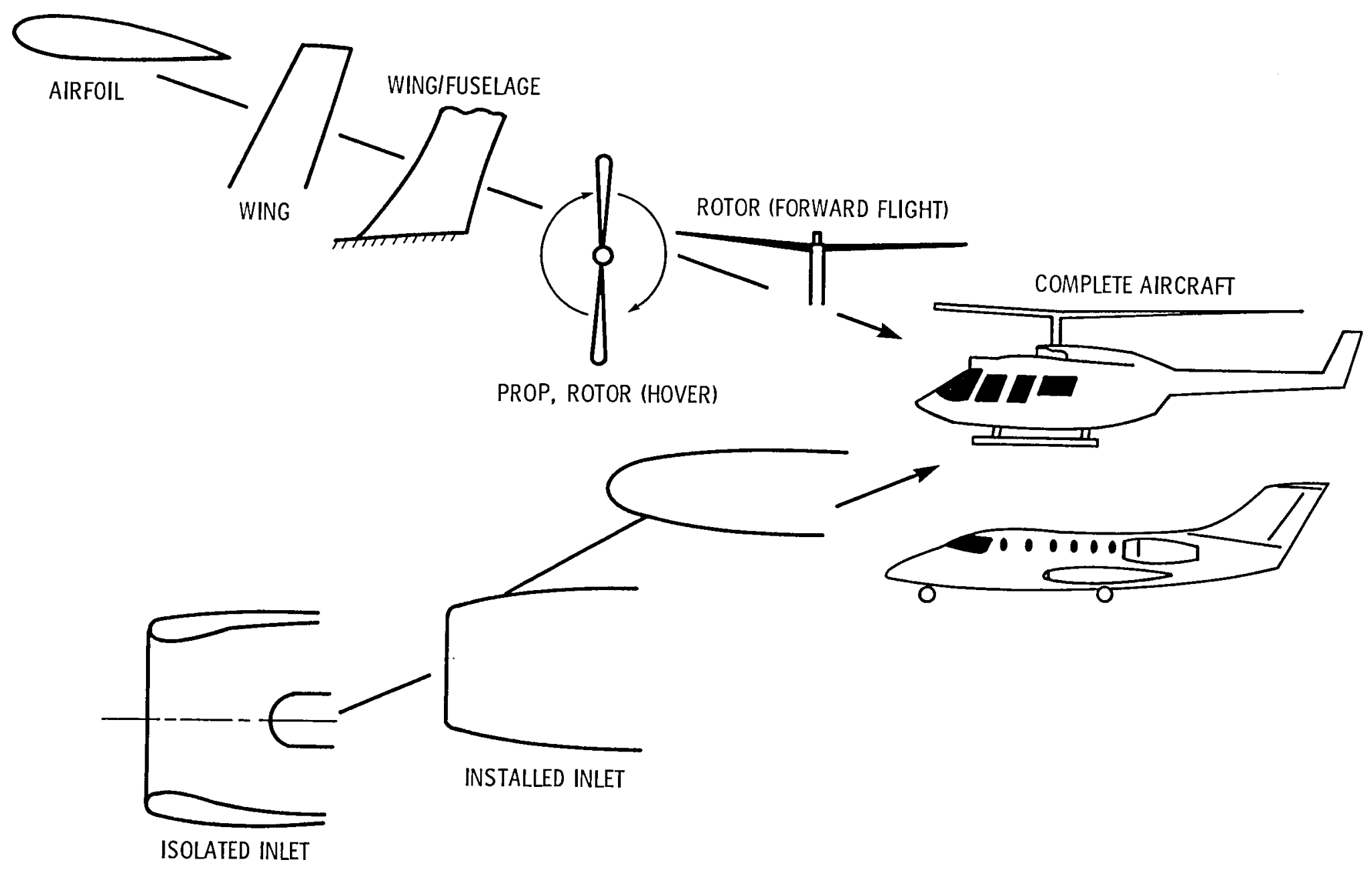

Figure 1. - Evolution of aircraft icing analysis capability. 
AERO ANALYSIS

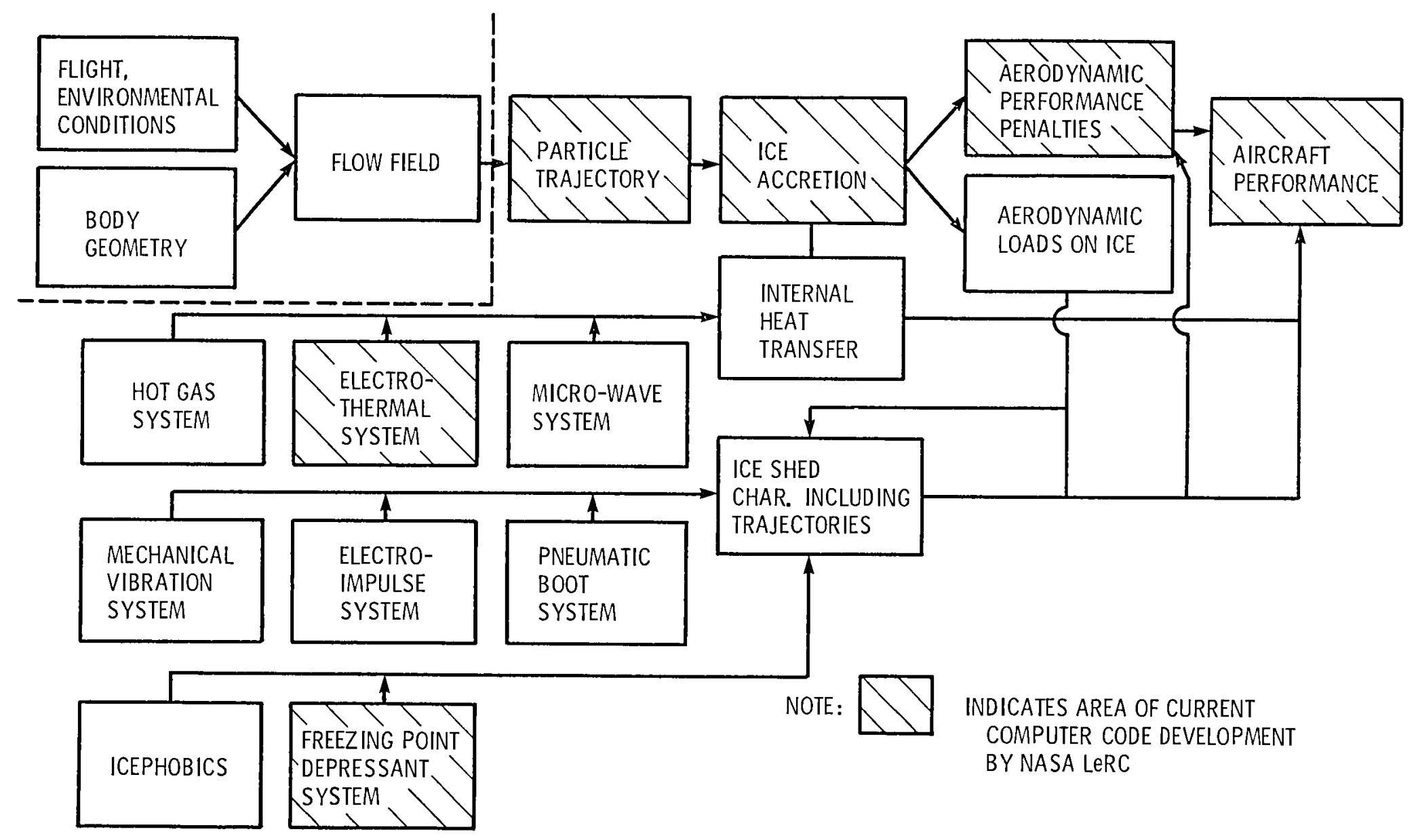

Figure 2. - Aircraft icing analysis methodology. 


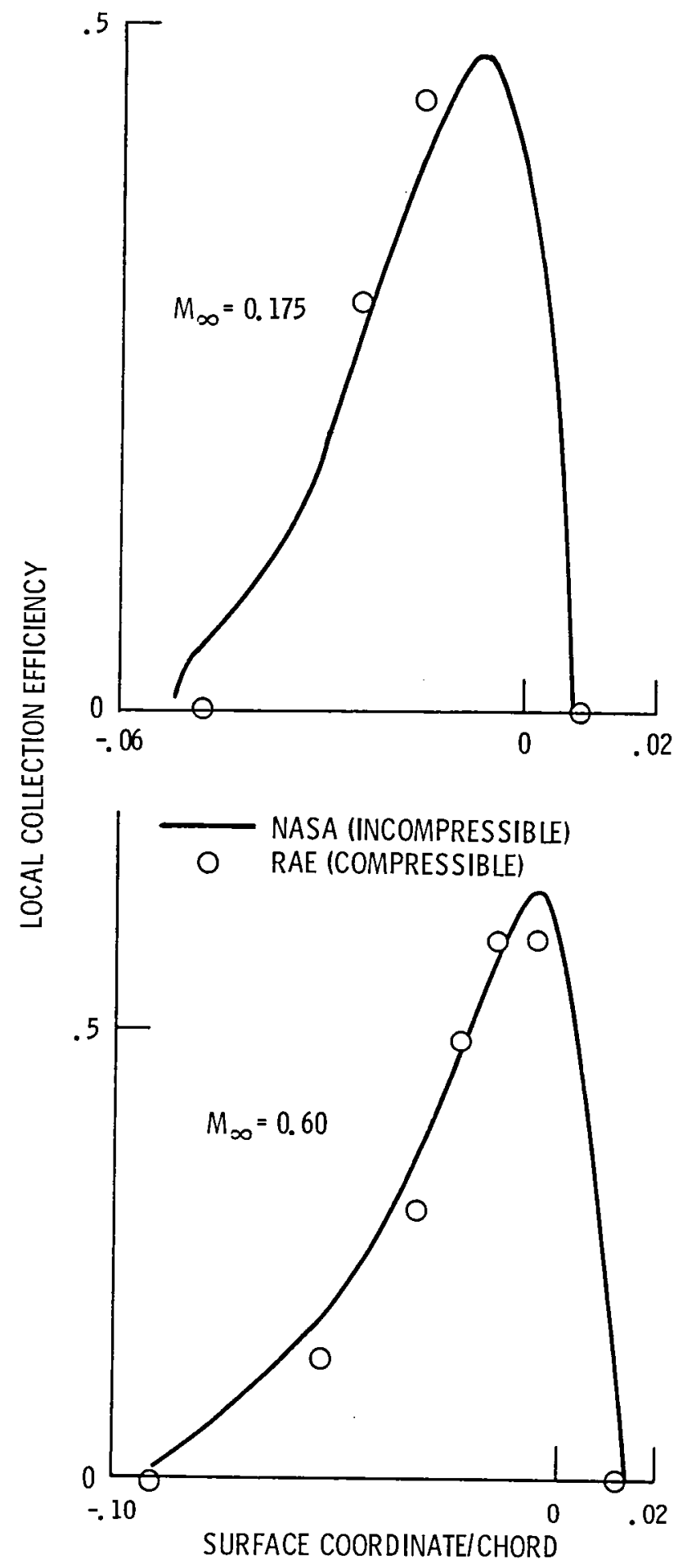

Figure 3. - Comparison of NASA/RAE water droplet trajectory analyses. NACA 0012 airfoil; chord $=21$ in. ; $\propto=4^{0}$; drop diameter $=12 \mu \mathrm{m}$. 


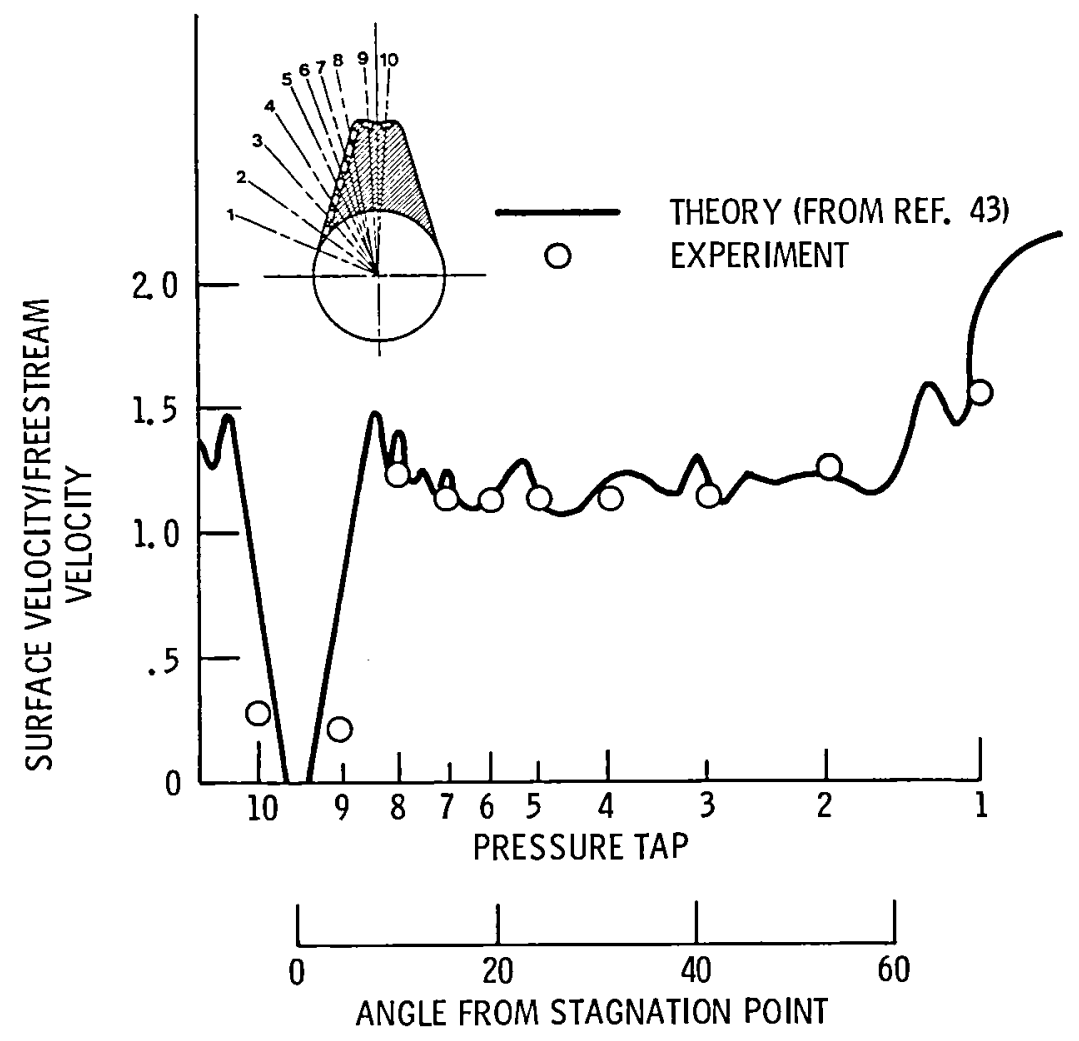

(a) 15 minute rime accretion.

Figure 4. - Cylinder ice shapes and velocity distributions. 


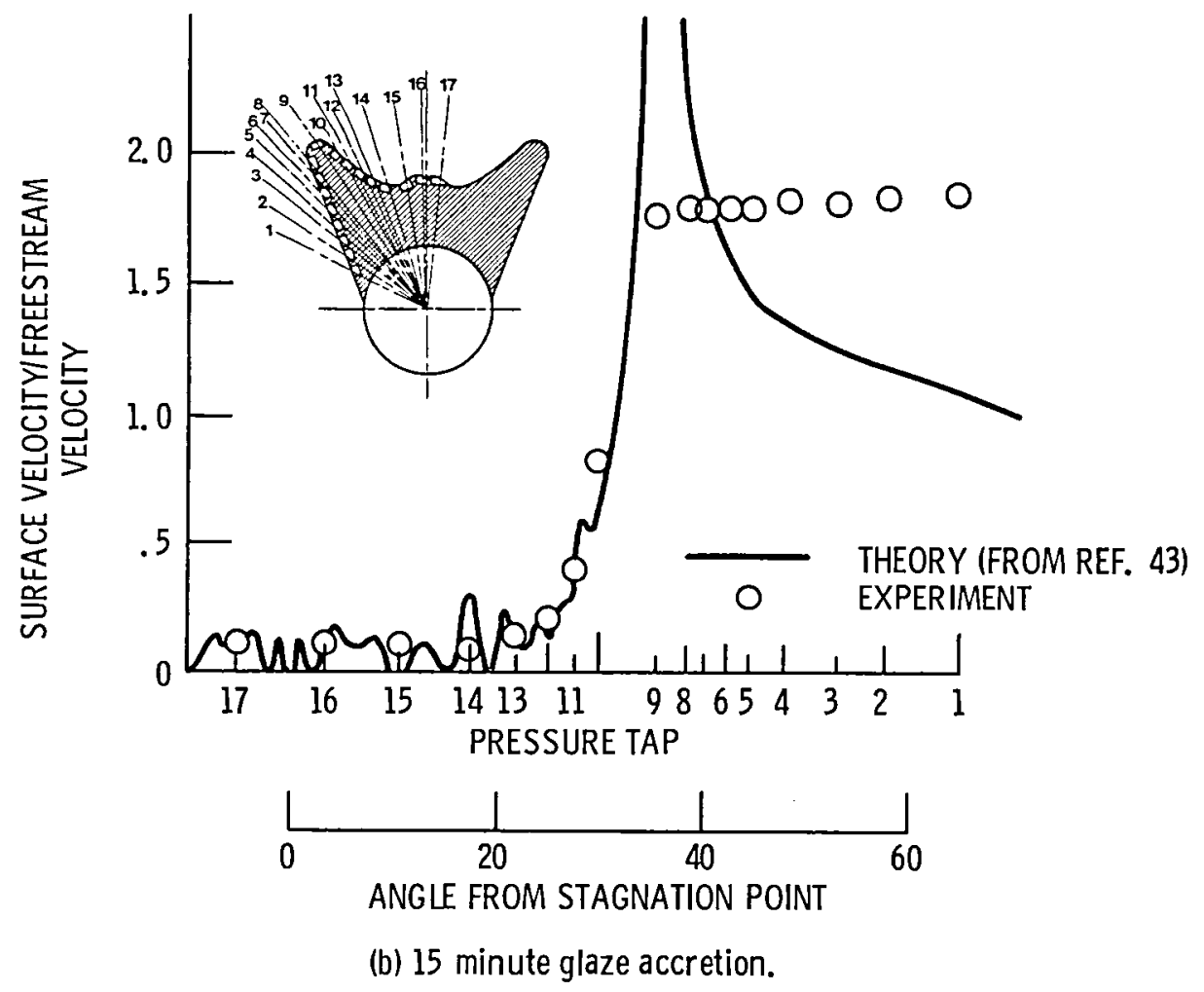

Figure 4. - Concluded. 


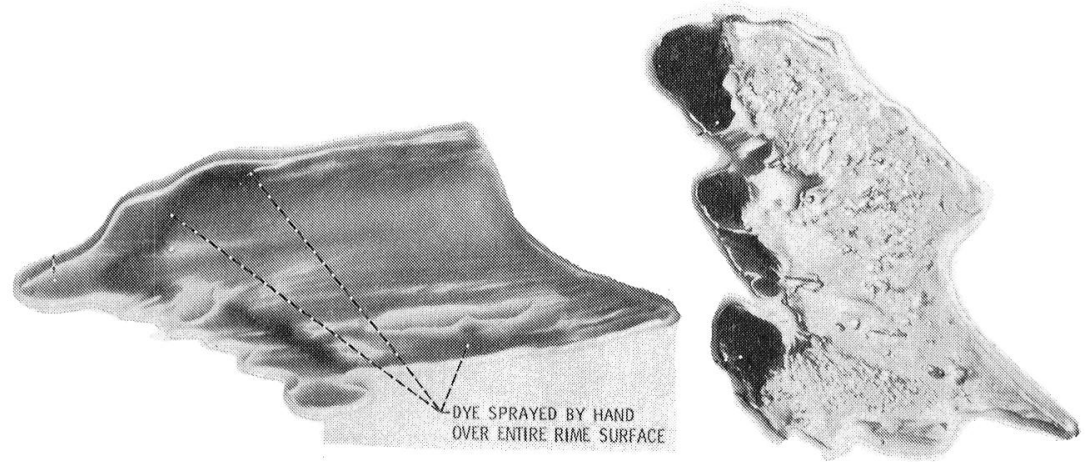

Figure 5. - Deter mination of local collection efficiency distribution for a NACA 0012 airfoil with rime and glaze ice accretions. (From ref. 46.) 

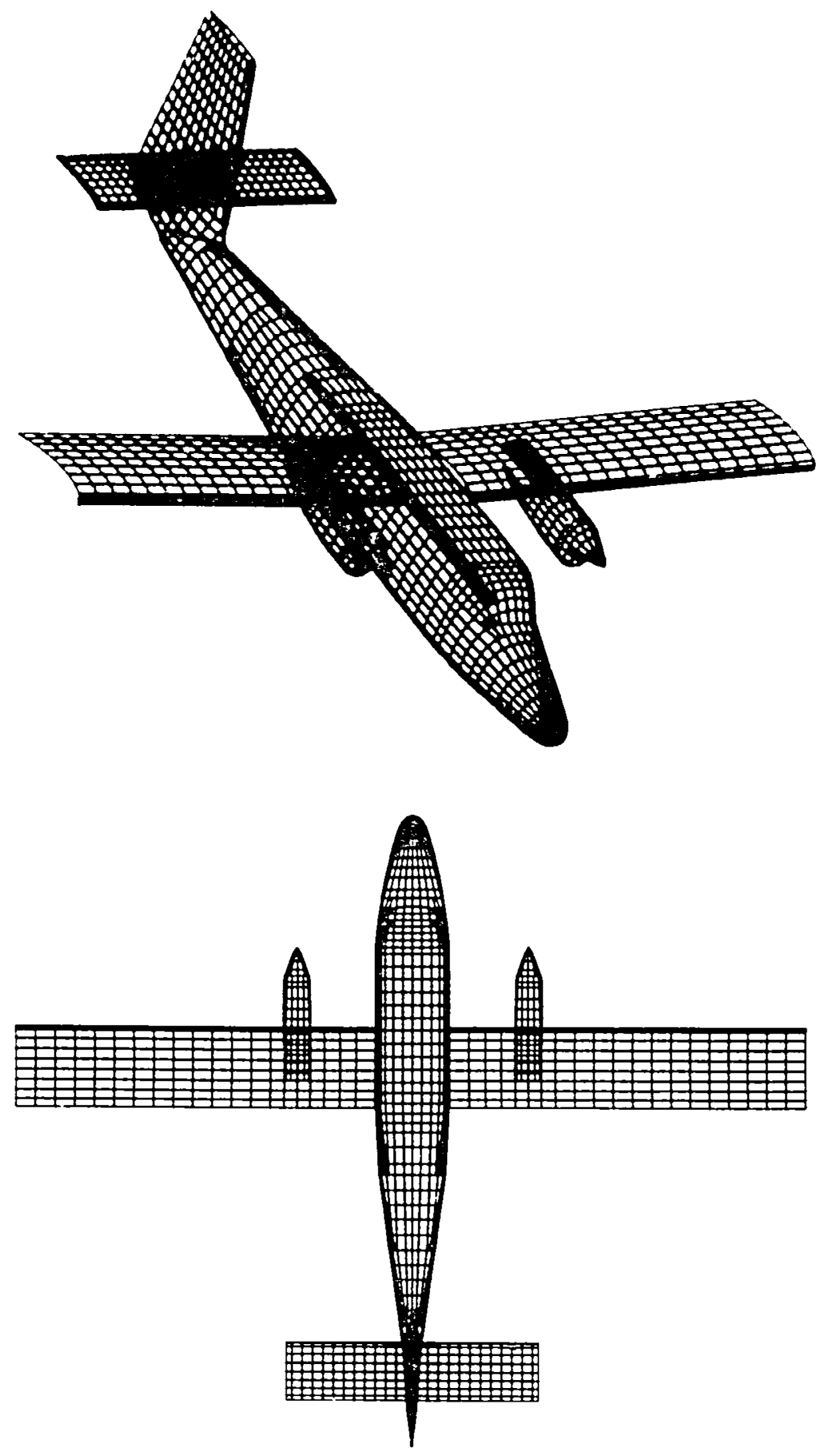

Figure 6. - Digital description of NASA icing research aircraft 


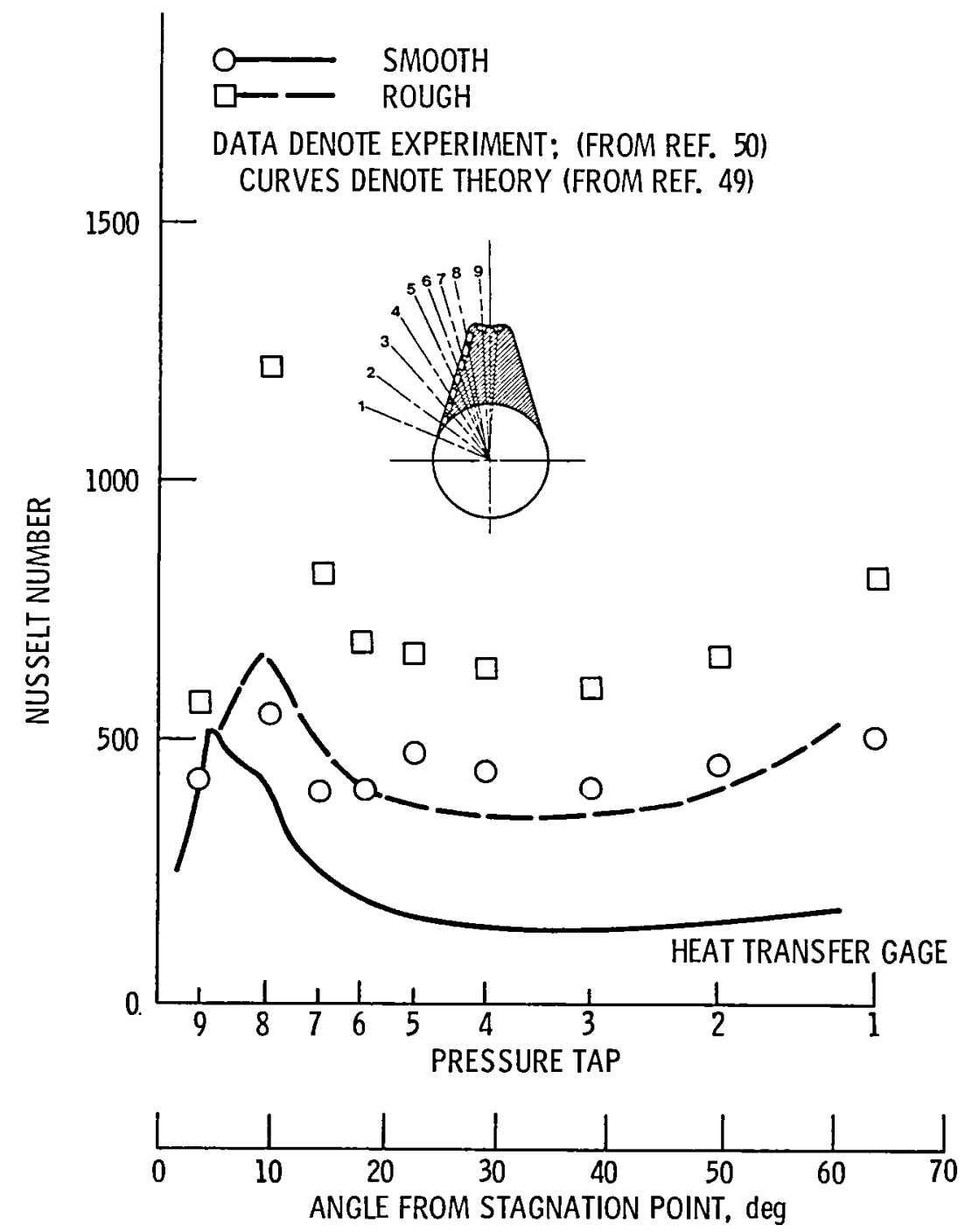

(a) 15 minute rime ice accretion.

Figure 7. - Comparisons of heat transfer coefficient predictions from LEWICE code with experimental measurements for smooth and rough ice shapes. 


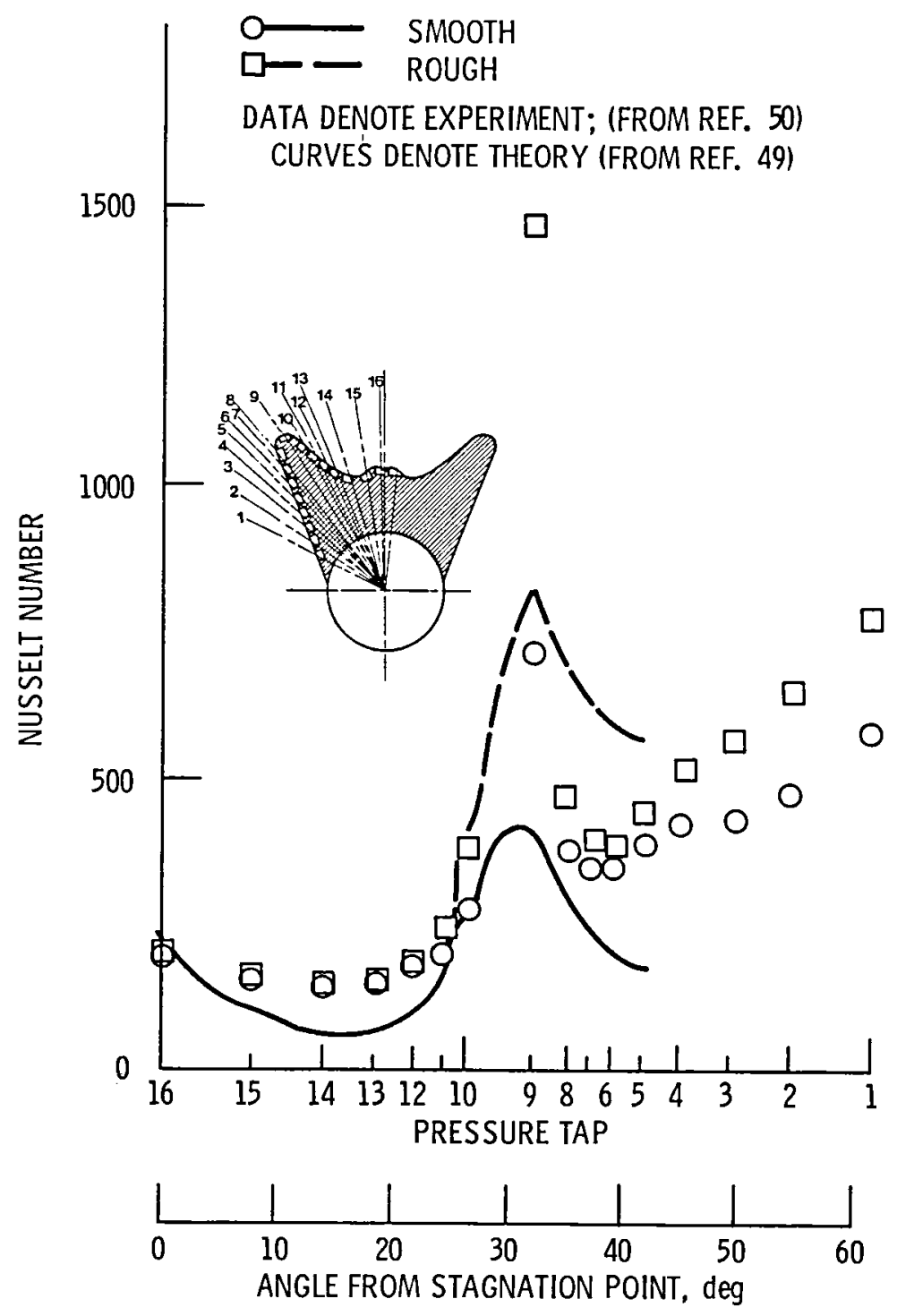

(b) 15 minute glaze ice accretion.

Figure 7. - Concluded. 


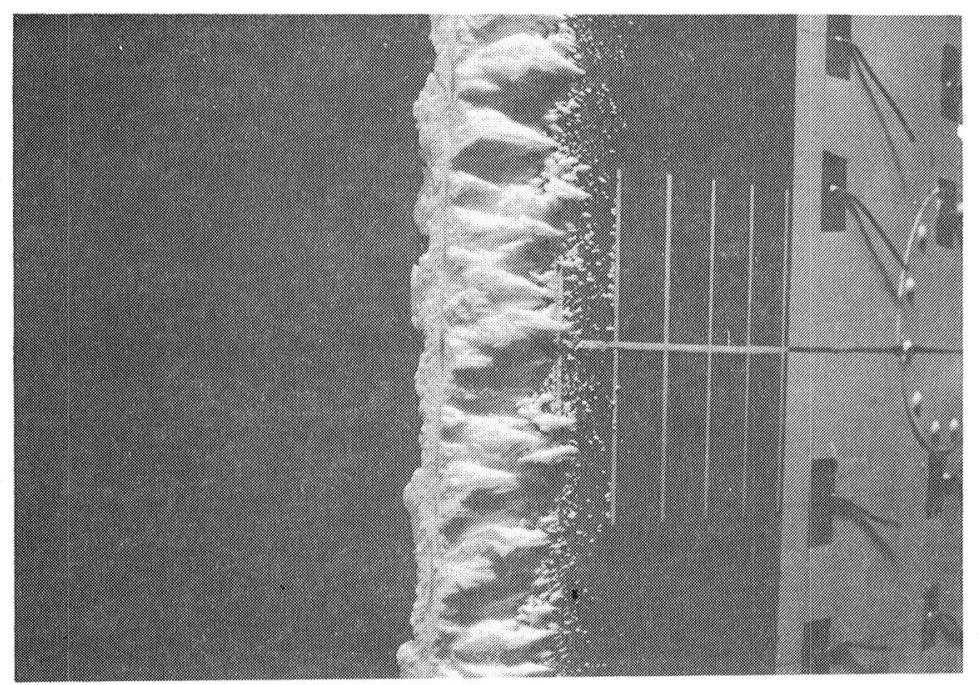

(a) Rime ice.

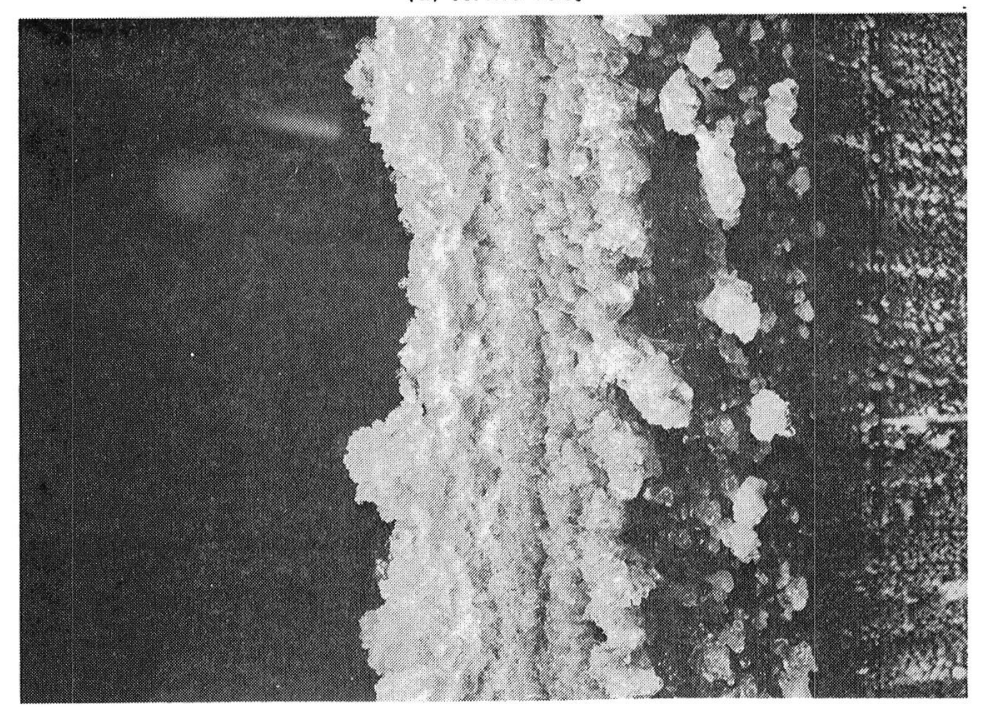

(b) Glaze ice.

Figure 8. - Close up photographs of rime and glaze ice accretions 


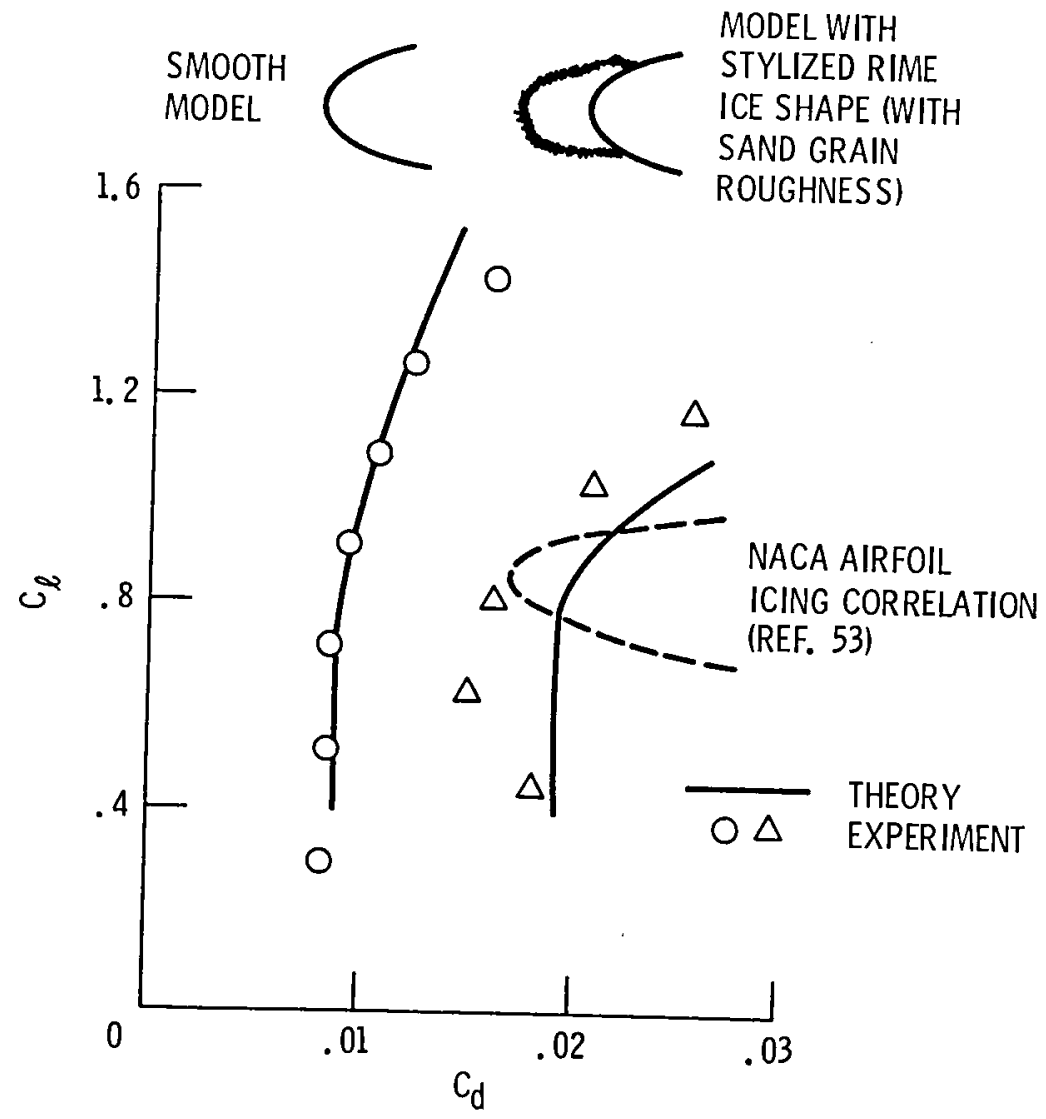

Figure 9. - Prediction of NACA 65-413 airfoil performance with simulated rime ice and comparison with experimental results.

$M_{\infty}=0.4 ; \mathrm{Re}=3 \times 10^{6}$. (From ref. 52.) 


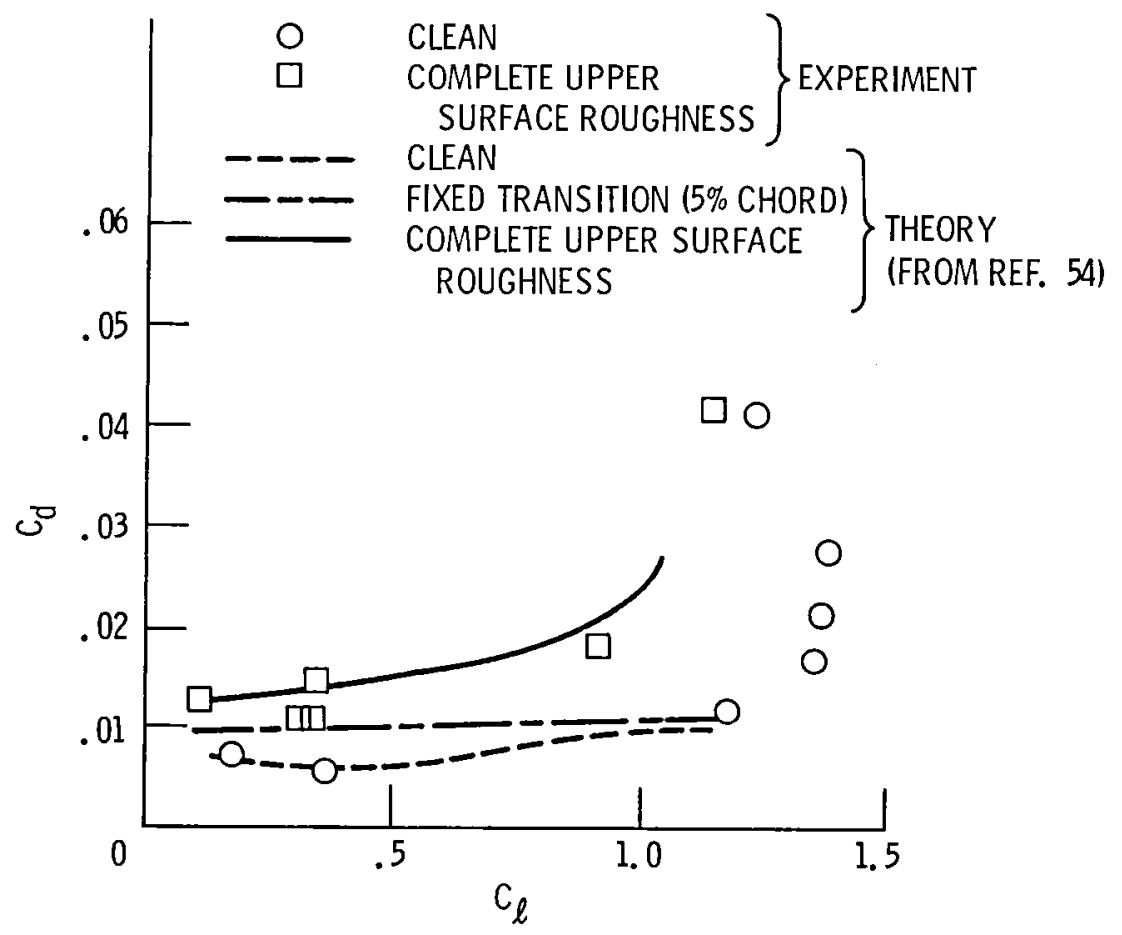

Figure 10. - Prediction of smooth and rough airfoil performance.

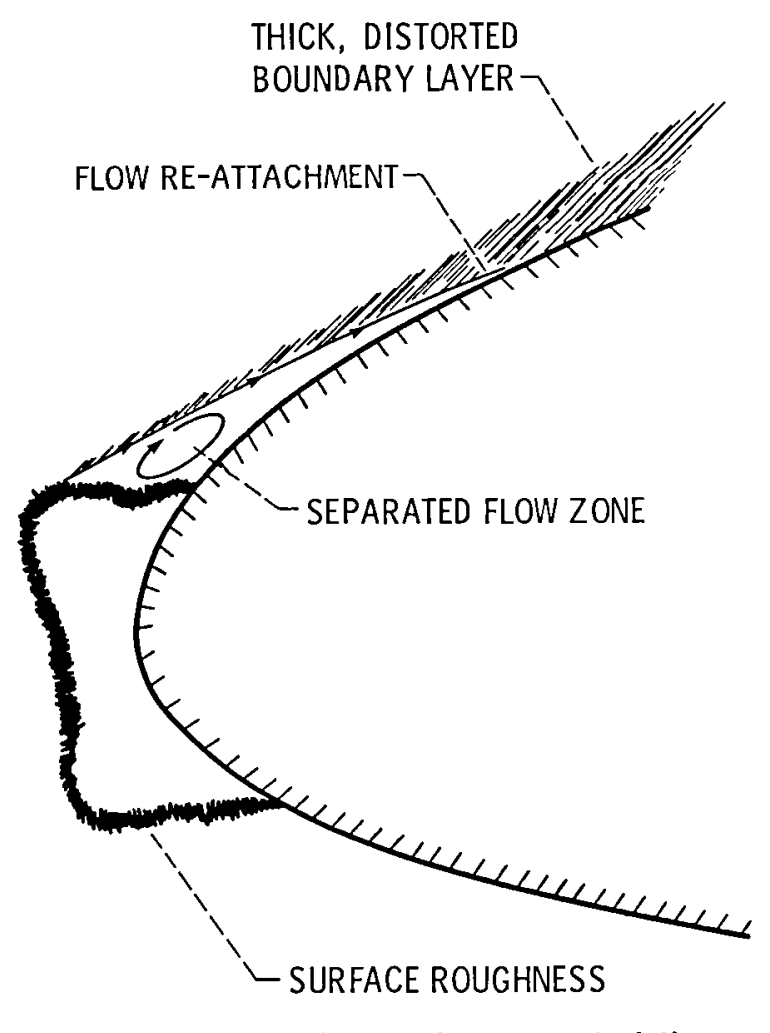

Figure 11. - Glaze ice flowfield characteristics. 


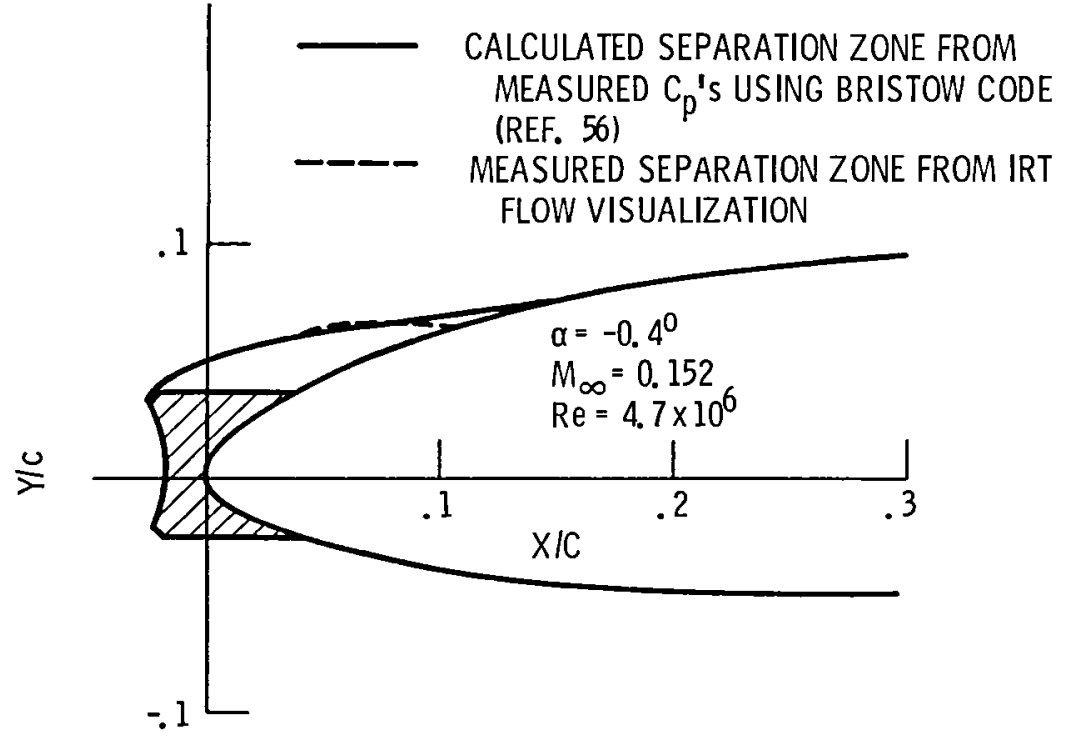

Figure 12. - Separation zone prediction from measured $C_{p}$ 's for the $63_{2}-A 415$ airfoil with glaze ice shape.

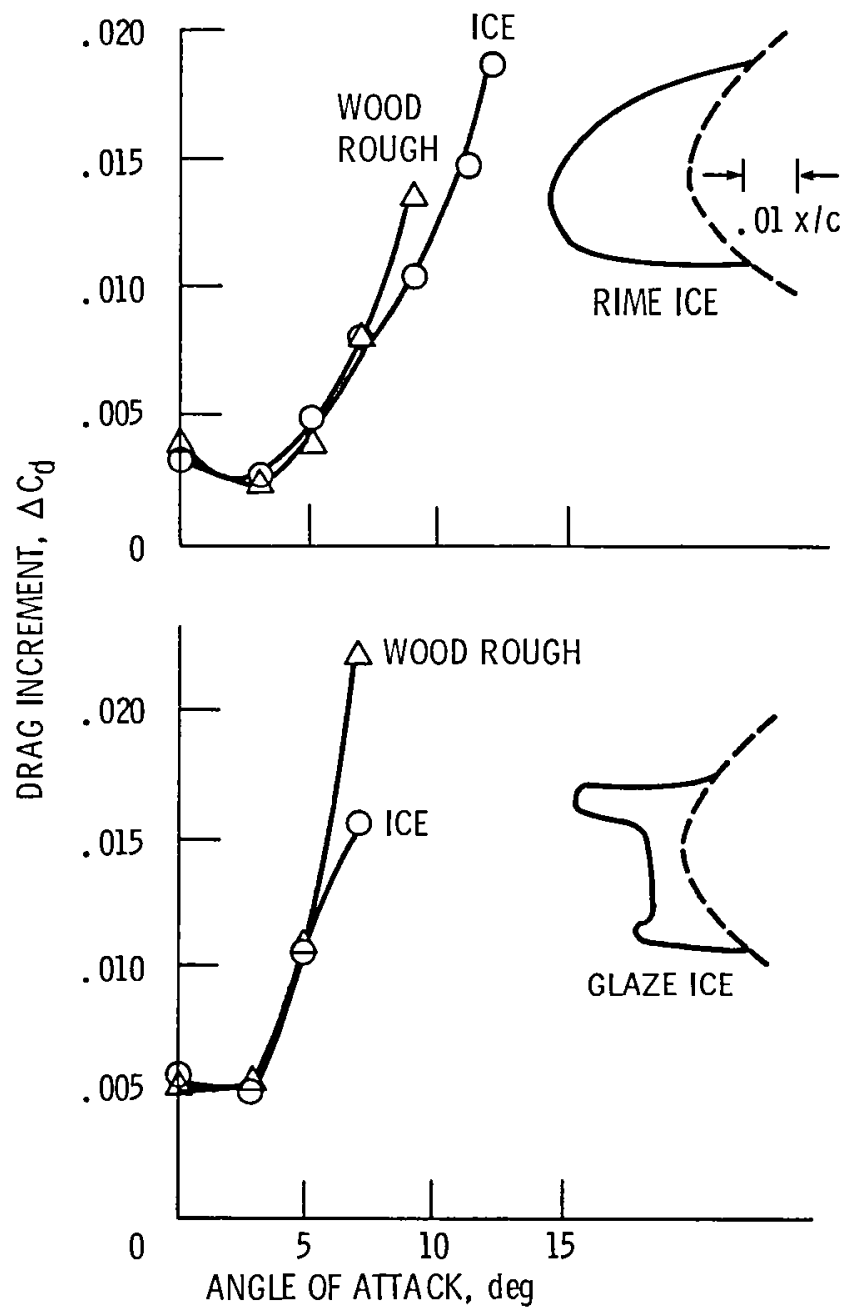

Figure 13. - IRT ice shape simulation studies using NACA $63_{2}-A 415$ airfoil. (From ref. 2.) 


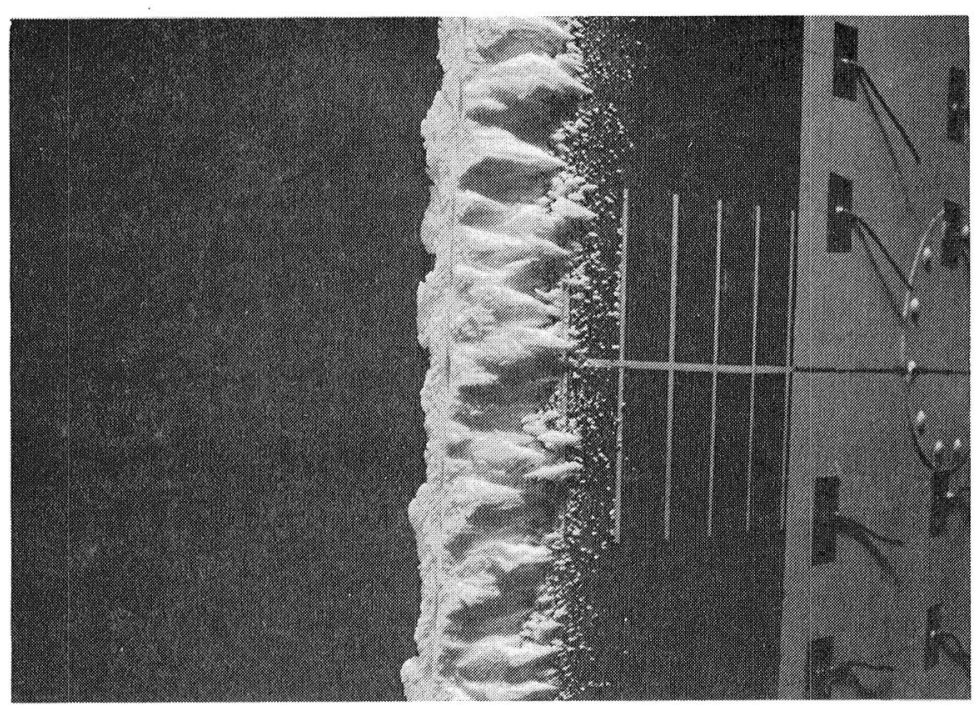

(a) IRT ice accretion.

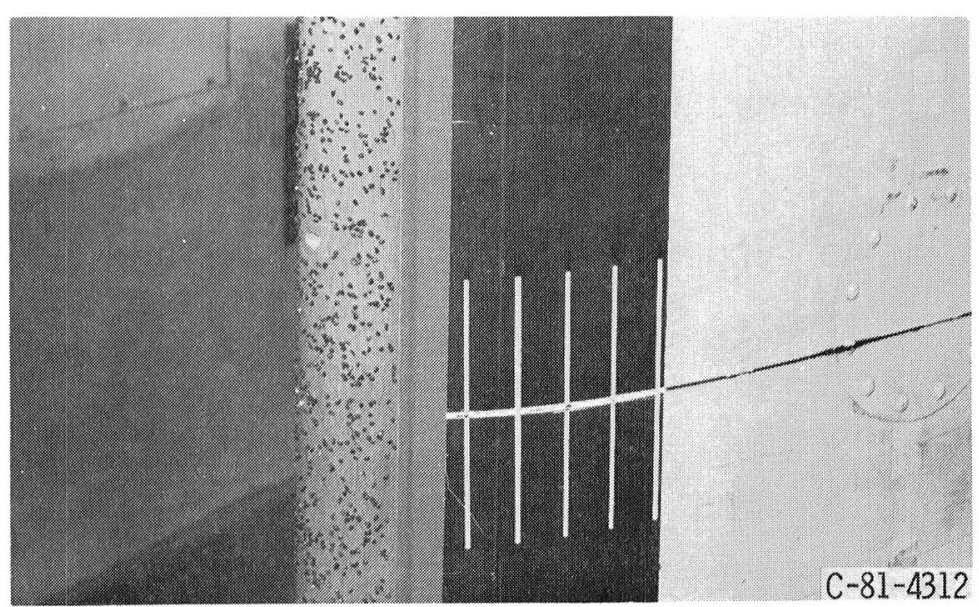

(b) Wooden ice shape simulation with sand grain roughness.

Figure 14. - Comparison of actual and artificial ice accretions. 


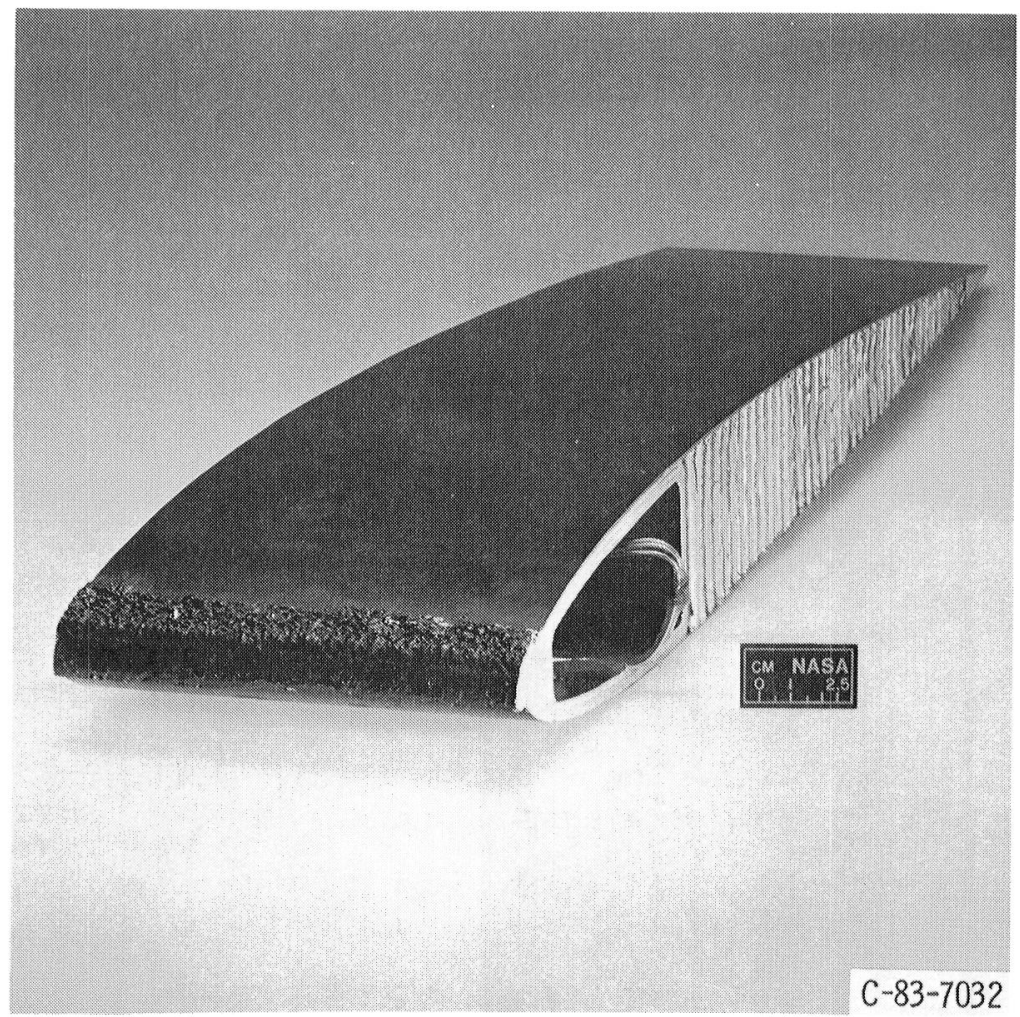

Figure 15. - Improved ice accretion si mulation approach.

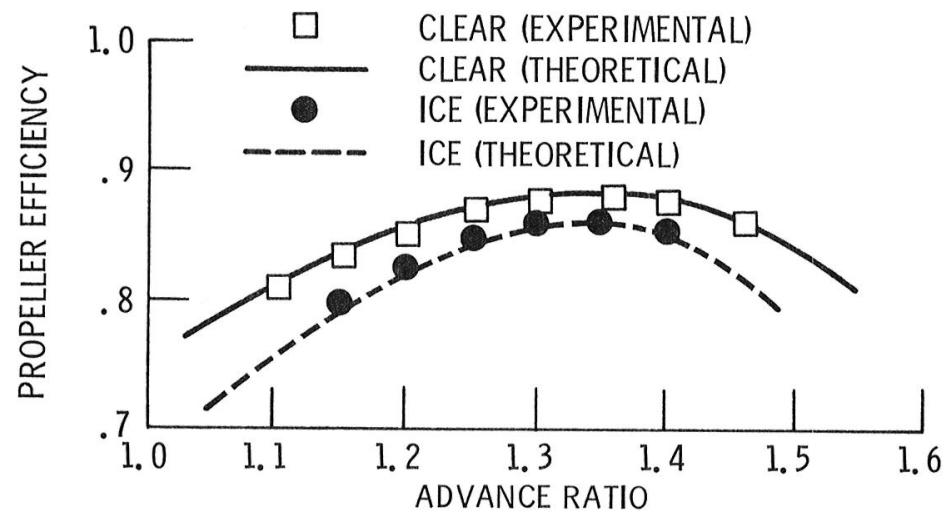

Figure 16. - Comparison between predicted and measur ed propeller performance in rime icing conditions. (From ref. 58.) 


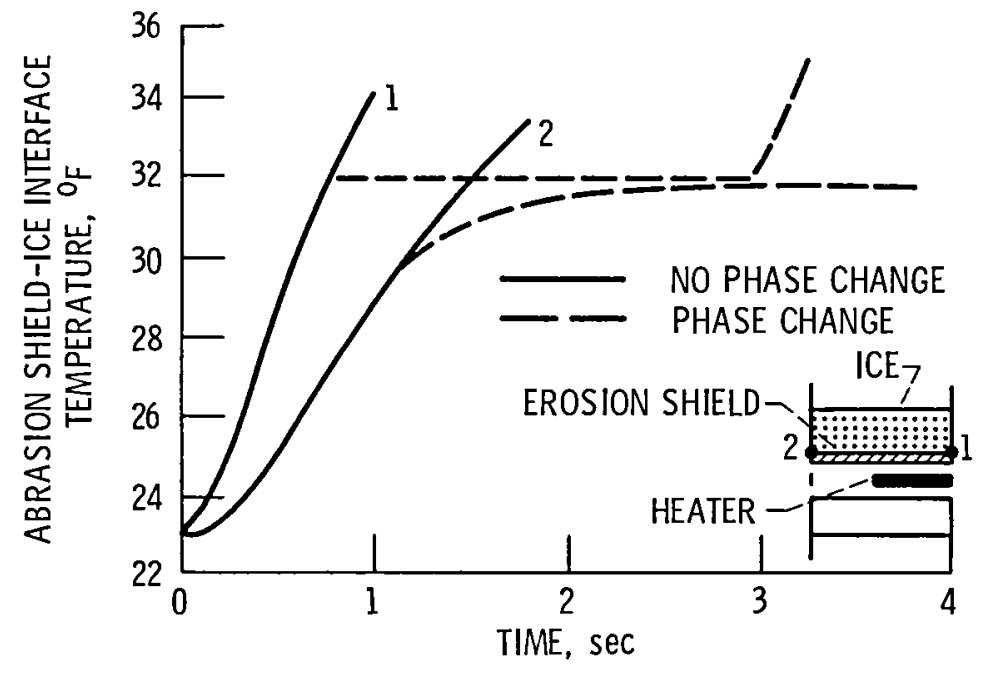

Figure 17. - Effects of phase change on predicted electrothermal deicer performance. (From ref. 69.)

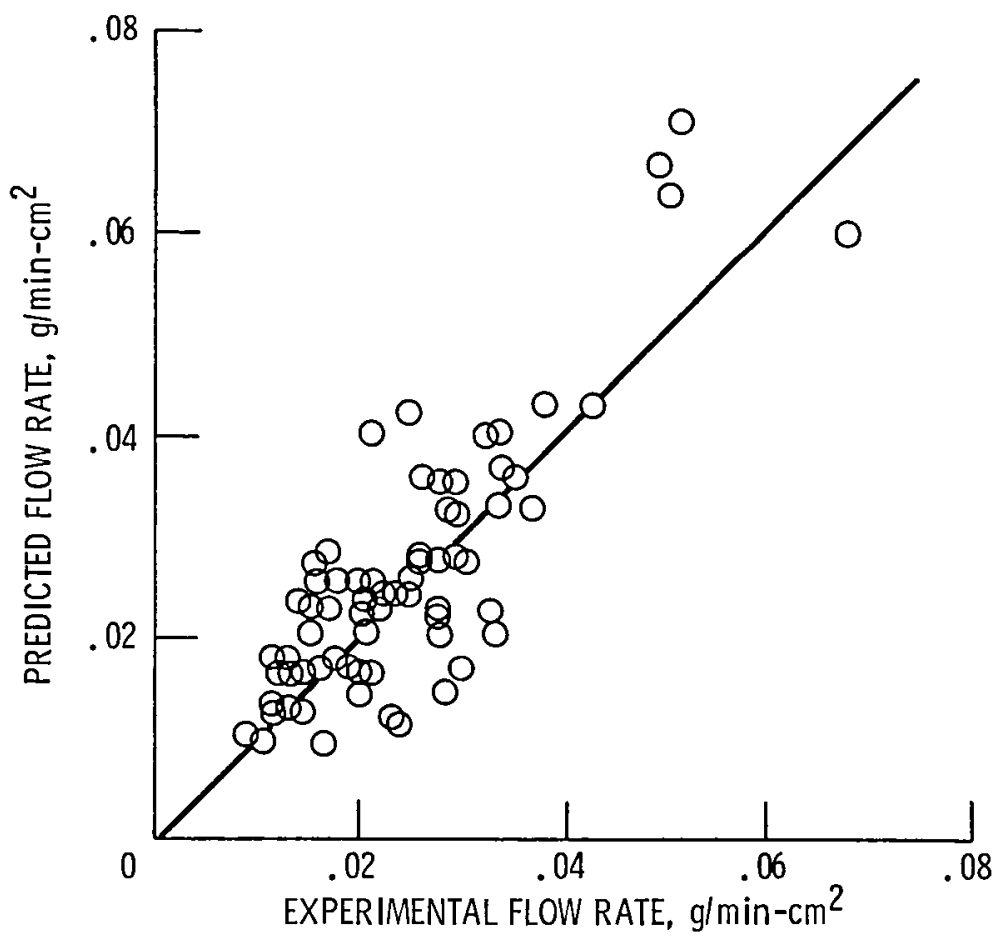

Figure 18. - Comparison of predicted and measured antiicing flow rates for the fluid freezing point depressant ice protection system. 


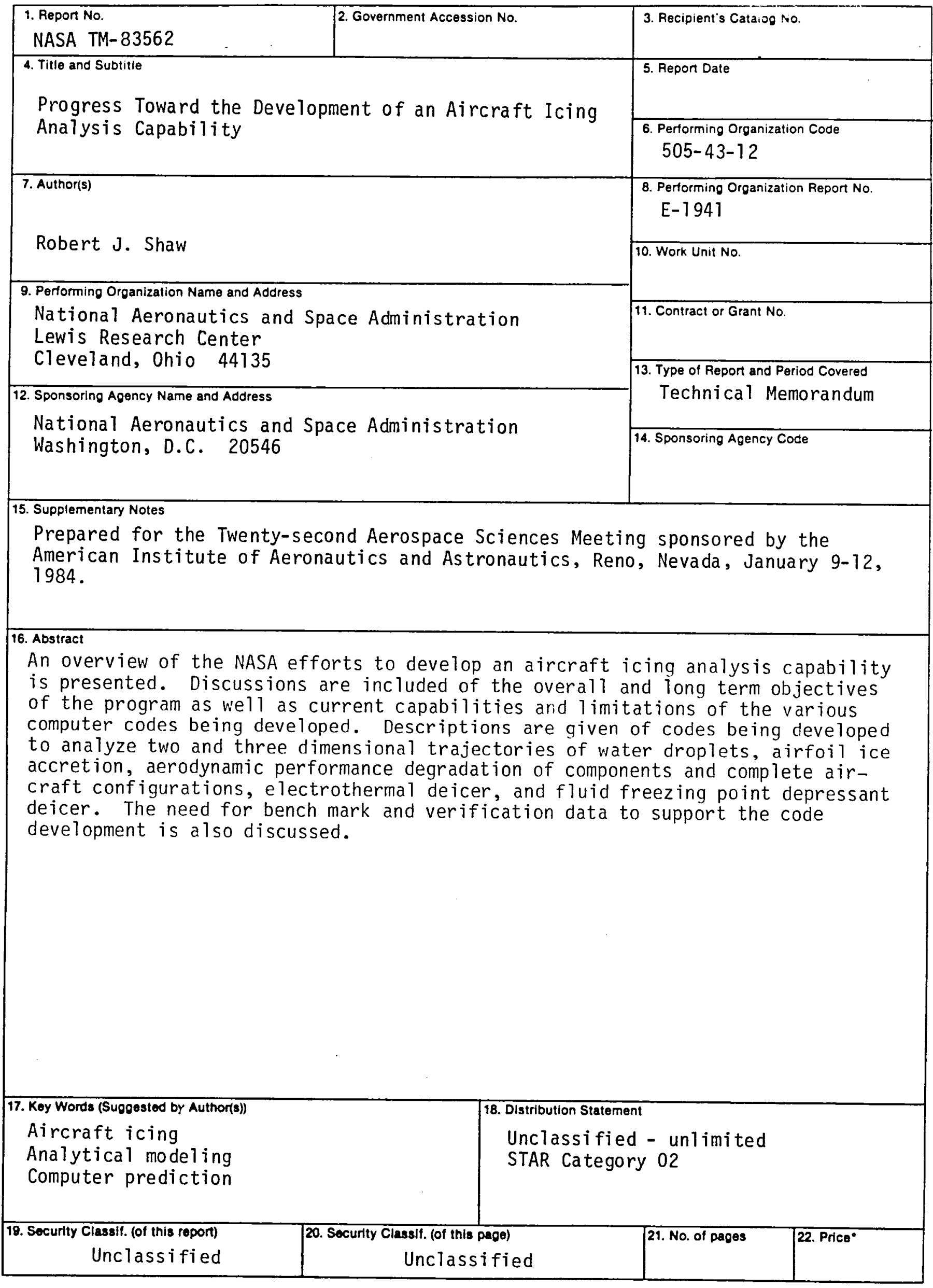

"For sale by the National Technical Information Service, Springfield, Virginia 22161 
2

$\omega$

,

, 
National Aeronautics and Space Administration

Washington, D.C.

20546

Otficial Business

Penalty for Private Use, \$3no
SPECIAL FOURTH SLASS MAIL

BOOK

\section{7}

Postage and Fees Paid National Aeronautics and Space Administration NASA-451 